\title{
Silvestris Zebolds
}

\section{THE CHOICE OF THE PLACEMENT OF ACETABULAR COMPONENT OF ENDOPROSTHESIS IN DYSPLASTIC OSTEOARTHRITIS PATIENTS}

Summary of Doctoral Thesis for obtaining the degree of a Doctor of Medicine Speciality - Traumatology and Orthopaedics 


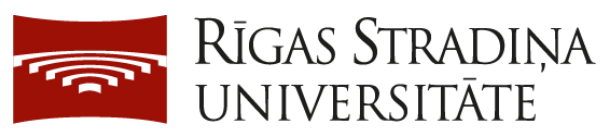

Silvestris Zebolds

\section{THE CHOICE OF THE PLACEMENT \\ OF ACETABULAR COMPONENT \\ OF ENDOPROSTHESIS \\ IN DYSPLASTIC \\ OSTEOARTHRITIS PATIENTS}

Summary of Doctoral Thesis

For obtaining the degree of a Doctor of Medicine

Speciality - Traumatology and Orthopaedics

Riga, 2014 
The Doctoral Thesis was carried out in:

Hospital of Traumatology and Orthopaedics;

National Rehabilitation Centre "Vaivari"

Scientific supervisor:

Dr. med., Associate Professor Andris Jumtiņš,

Rīga Stradiņš University

Official reviewers:

Dr. habil. med., Professor Andrejs Skaǵers, Rīga Stradiņš University

Dr. med., Gundars Lācis, RAKUS "Gaiḷezers"

Dr. med., Associate Professor Manvilius Kocius, Vilnius University

The defense of doctoral thesis will be held on the $8^{\text {th }}$ of January, 2014 at 3.00 p.m. in the open meeting of the Promotion Council, Rịga Stradinš University, in the Lecture theatre Hippocrates, 16 Dzirciema Street, Riga.

The doctoral thesis is available at the library of RSU and on the RSU home page: www.rsu.lv

The Doctoral Thesis was supported by European Social Fund Project "Support to implementation of doctoral study programmes and obtaining the scientific degree in RSU"
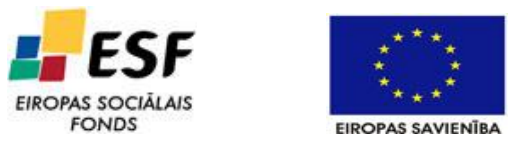

leguldījums tavā nākotnē!

Secretary of the Promotion Council:

Dr. habil. med., Professor Andrejs Skaǵers 


\section{CONTENTS}

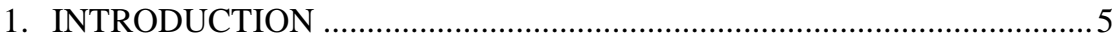

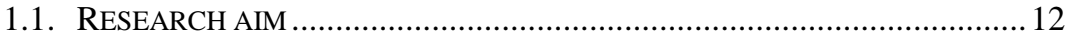

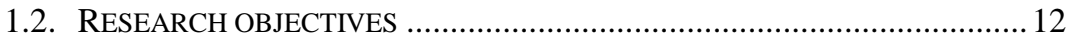

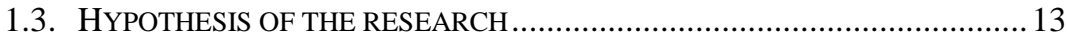

1.4. SCIENTIFIC NOVELTY OF THE RESEARCH …....................................... 13

1.5. PRACTICAL SIGNIFICANCE OF THE RESEARCH.................................... 13

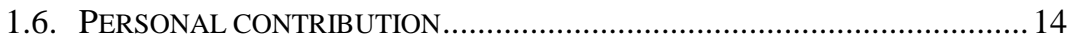

1.7. STRUCTURE OF THE THESIS AND ITS VOLUME ....................................... 14

2. MATERIAL AND METHODS …........................................................... 15

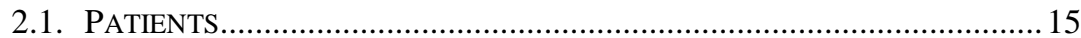

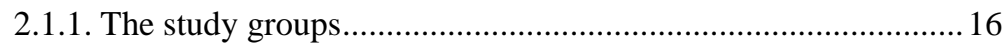

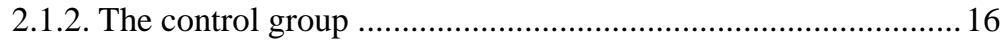

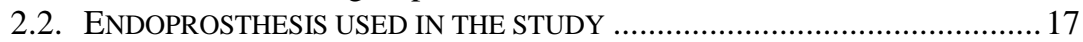

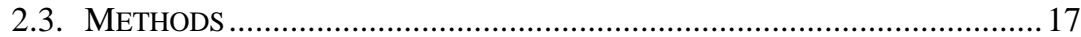

2.3.1. Devices used for measurements........................................... 17

2.3.2. The method used in the study to evaluate clinically functional status of patients .................................................... 17

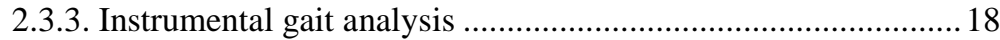

2.3.4. Gait deviation index................................................................ 19

2.3.5. Radiographic investigation of DOA patients ...........................20

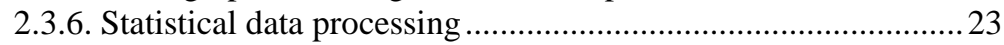

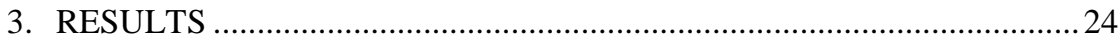

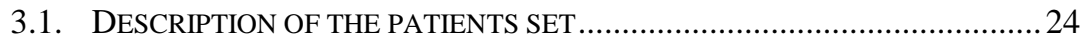

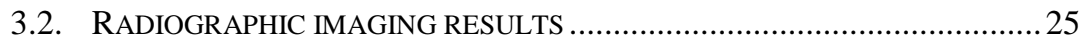

3.3. DOA PATIENTS' CLINICAL-FUNCTIONAL RESULTS .................................. 30

3.3.1. Grading by Merle-d'Aubigne-Postel method ............................30

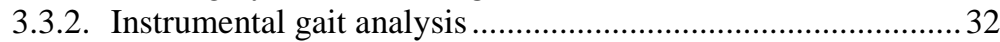

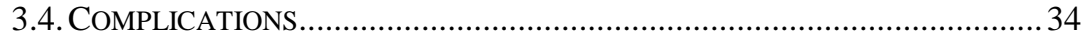

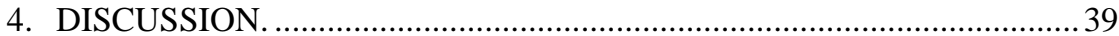

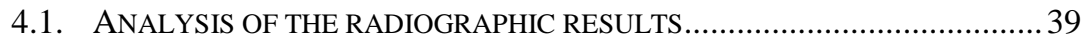

4.2. ANALYSIS OF THE FUNCTIONAL RESULTS …...................................... 41

4.3. ANALYSIS OF FUNCTIONAL LEG LENGTH DIFFERENCE ........................ 43

4.4. ANALYSIS OF COMPLICATIONS ........................................................4 
5. CONCLUSIONS 50

5.1. CONCLUSIONS ABOUT PRE- AND POST-OPERATIVE RADIOGRAPHIC ANALYSIS OF DOA PATIENTS 50

5.2. CONCLUSIONS ABOUT ANALYSIS OF DOA FUNCTIONAL RESULTS (PRE- AND POST-OPERATIVE).

5.3. CONCLUSIONS ABOUT EVALUATION OF POST-OPERATIVE COMPLICATIONS IN RELATION TO THE PLACEMENT OF ACETABULAR COMPONENT OF ENDOPROSTHESIS................................................. 52

RESUME 52

6. PRACTICAL RECOMMENDATIONS .................................................... 53

7. PUBLICATIONS ABOUT THE STUDY TOPICS .................................... 55

8. REPORTS ABOUT THE RESEARCH TOPIC ...................................... 56

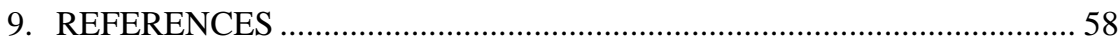




\section{INTRODUCTION}

Dysplastic osteoarthritis (DOA) is affecting mostly young people of working age with a history of congenital hip dysplasia or congenital luxation. Due to dysplasia of hip joint, joint's cartilage is biomechanically loaded incorrectly, it wears out, and secondary osteoarthritis develops [1,2], joint space narrowing as a result of cartilage wear is radiographically visible. Joint socket is shallow, elongated (undeveloped), femoral head is oval in shape, femoral neck is steep (in valgus position, anteverted), femoral canal is often very narrow (Fig. 1).

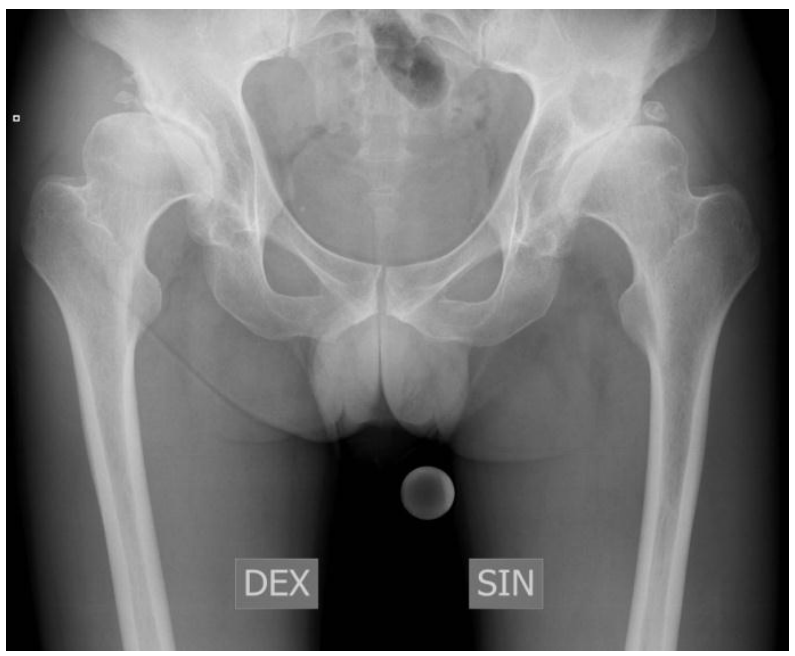

Fig. 1. Radiograph of pelvis in A-P projection Dysplastic osteoarthritis of both hip joints

Clinical symptoms of DOA are directly related to the severity of dysplasia as well as the age of the patient [1]. Dysplastic osteoarthritis clinical manifestations are: pain, limitation of movement, limping, in severe cases patients can move around only with the help of walking aids (canes or crutches). Often, patients' gait varies greatly from a normal human gait. DOA 
patients are characterized by a gluteal muscle weakness which manifestates itself as a waddling gait.

Arthroplasty is one of the main methods of treatment $[3,4]$ that provides for patients a chance to improve quality of life, to return them to an active social life. These operations are aimed at reducing pain, increasing range of motion, and at functional improvement of the affected joint [5]. During the replacement surgery at the affected hip joint, it is replaced with an artificial one (Fig. 2).

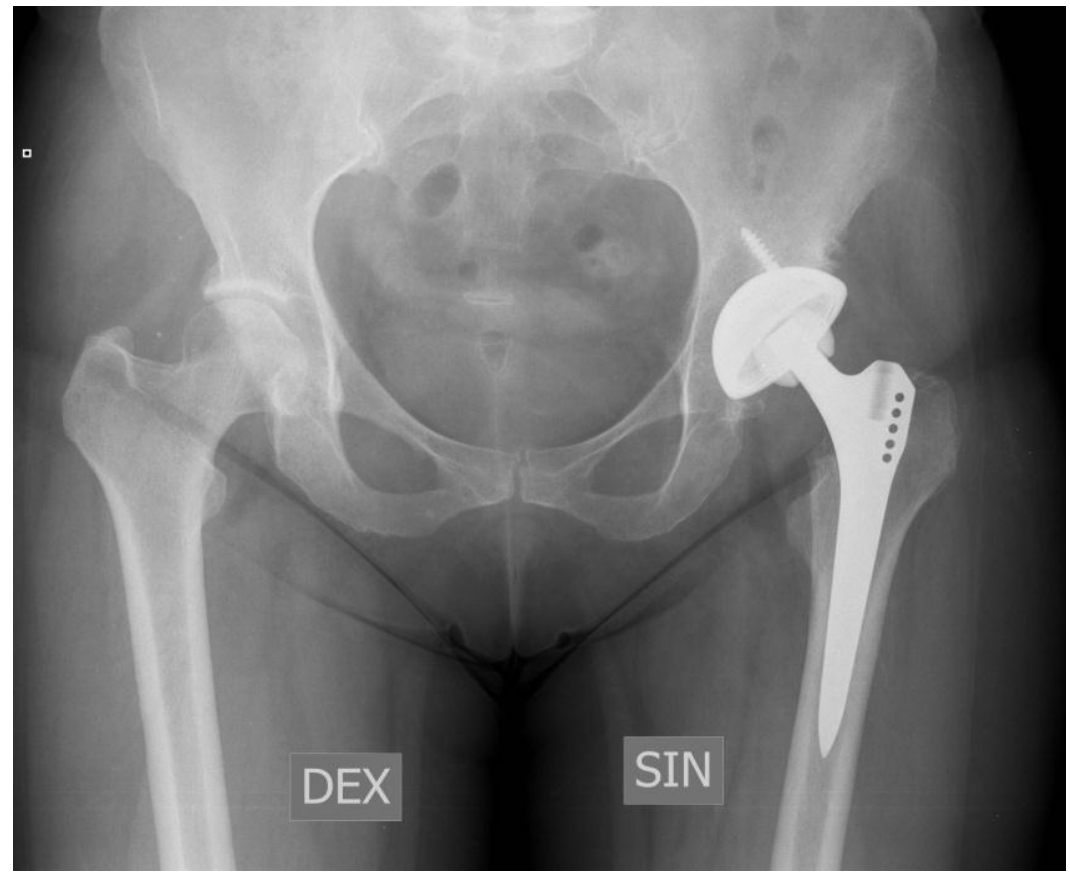

Fig. 2. Radiograph of pelvis in A-P projection Cementless fixation endoprosthesis of left hip

A standard endoprosthesis (EP) consists of artificial joint's socket (acetabular component of endoprosthesis), endoprosthesis stem (femoral component of endoprosthesis which is fixed in the femoral canal) and endoprosthesis head (Fig. 3). 


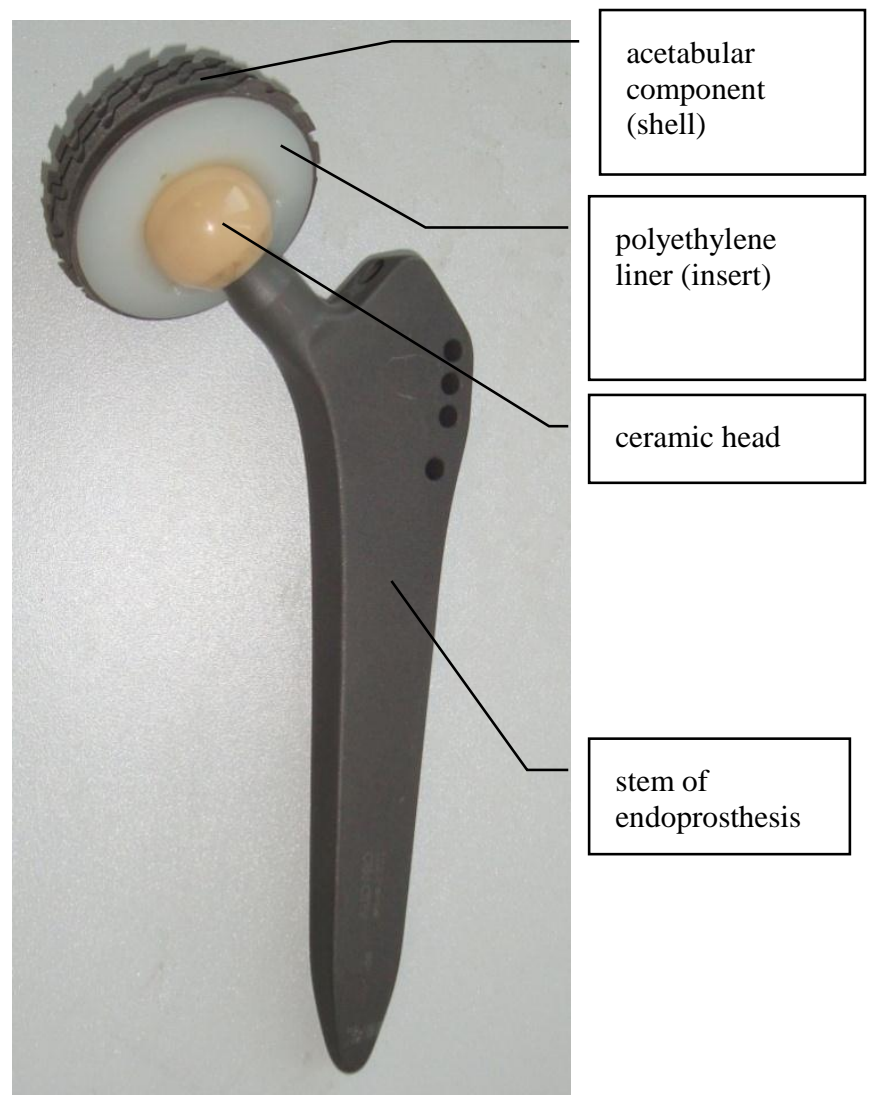

Fig. 3. Cementless endoprosthesis of hip joint

Depending on the type of endoprosthesis fixation in the bone, there are 2 types of endoprosthesis - with cementless fixation and with cement fixation. Young active people generally are applied cementless or biological fixation of endoprosthesis. Acetabular component of cementless EP consists of 2 parts: metallic shell and polyethylene (or ceramic) insert.

Cementless EP of hip is typically made from titanium. EP surface, which is in contact with the bone, is porous in order to ensure the bony ingrowth. It is believed that bony ingrowth takes about 6-8 weeks. 
Cementless EP acetabular components, depending on the type of the primary fixation, can be either press fit, or screwed-in - with external thread. To ensure sufficient primary mechanical fixation, it's possible to use 2 types of screwed-in acetabular components: with holes, which may be used for additionally fixing acetabular components with screws to the pelvis (Fig. 4.), and without holes.

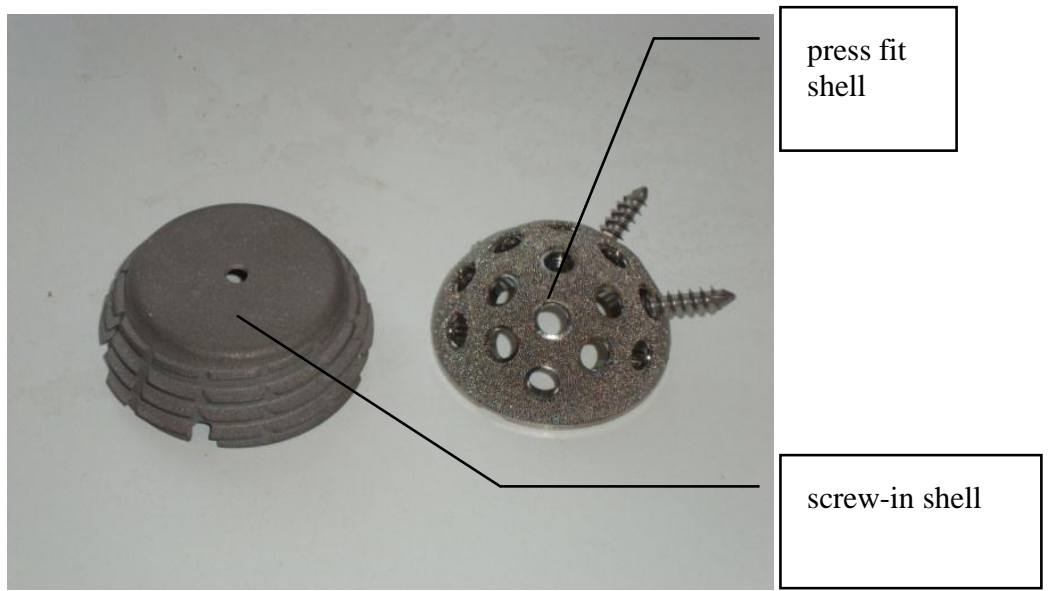

Fig. 4. Acetabular components of endoprosthesis of hip joint

The cement fixation endoprosthesis (commonly used for elderly patients) is attached to bone with the help of special bone cement.

Total hip replacement (THR) is one of the world's most popular operations. In UK, there are carried out approximately 70,000 [6] total hip replacement or arthroplasty operations per year, and in the United States - even 250,000 [7].

In Latvia, total hip replacement was launched in the Latvian Scientific Research Institute of Traumatology and Orthopaedics (under the leadership of academician V. Kalnberzs) in eighties of the last century. This method of treatment gained widespread application after Latvian independence restoration. Invaluable contribution to the development of arthroplasty in Latvia was given by the famous American orthopedic of Latvian origin professor K. 
Keggi of Yale University. At his clinic in Waterbury (USA, Connecticut), most Latvian surgeons, which specialize in arthroplasty, have completed their internships (among them - also the author). In Latvia, 1500 - 2000 total hip replacement operations are performed annually, most of them - in the State Hospital of Traumatology and Orthopaedics (SHTO), Riga. Patient satisfaction level after replacement surgery is considered to be one of the highest among orthopedic surgery operations.

Due to pronounced anatomical changes (hip joint socket is underdeveloped: shallow and elongated, the femoral head is not in full contact with the articular surface, commonly seen is lack of mass in the pelvis forming bones which could be used for stable insertion of the acetabular component of endoprosthesis), hip arthroplasty in patients with DOA is regarded as a complicated surgical operation [8-13]. Complications, if compared with degenerative OA patients, are considerably higher. Survival of endoprosthesis is characterized by the percentage of patients who need revision operation due to any of the complications. Many countries have set up registers of endoprosthesis to be able to assess and compare results of the replacements in a specific period of time. One of the most popular is the Swedish Hip Arthroplasty Register. According to the data of this registry for the year 2012, ten years after primary total hip replacement surgery the revision operation was not necessary for $95 \%$ of patients which have been operated in Sweden. Unfortunately, in Latvia no common endoprosthesis register across the country have been created yet. Only in the State Hospital of Traumatology and Orthopaedics after several attempts to introduce the register, since 2011, computer data processing of all primary and revision joint replacements was started. Hopefully, the registry developed by SHTO will become a foundation for the Latvian Endoprosthesis register.

Results of replacement depend largely on how stable is primary fixation of the EP components. 
Although in patients with dysplasia, often observed are also the femoral development peculiar features (narrow femoral canal, neck is anteverted and in valgus position), the main problem is to achieve sufficient coverage of the acetabular component of EP by bone.If coverage is inadequate, acetabular component may start loosening too early which leads up to repeated operation (revision). Due to changed anatomy of acetabulum, there is a possibility that during already the primary replacement operation acetabular socket might need reconstruction using bone grafts [14] to compensate for the missing bone mass. Some authors [15] recommend cementing acetabular component of endoprosthesis in combination with a bone transplant. Others [14, 16] recommend the use of small cementless acetabular components in order to achieve a stable fixation of endoprosthesis in pelvis. The aseptic (mechanical) loosening of acetabular component of EP is the most frequent complication. According to the Swedish Hip Arthroplasty Register data, $75 \%$ of revision operations are caused by mechanical loosening of EP. One of the most common complications, following total hip replacement in patients with dysplastic osteoarthritis, is also a luxation of endoprosthesis head [17] which is largely associated with both acetabular component's position in pelvis and the condition of soft tissues surrounding the joint (muscles, tendons, capsule). Also, the condition of pelvis itself (e.g., oblique pelvis) can sometimes be a luxation contributing factor.

A long period of observations shows a relatively large number of cases with loosening of acetabular component of endoprosthesis. Some authors point out that after seven years already $20 \%$ of acetabular components are loose; after twelve years number of loose acetabular components reaches as much as $46 \%$, in addition, $20 \%$ of the operated patients were in need of revision operations [18]. Survival of endoprosthesis is also influenced by the fact that DOA patients are young and active [19] (as opposed to degenerative OA patients). Active life style contributes to an early EP component wear what can lead to 
the need for the revision operation. Due to young age of patients, as a rule, cementless fixation endoprosthesis are used, and that is because generally then the revision replacement surgery is easier and faster executed. Review of cementless EP shows that bone mass loss is smaller compared to the cement fixation of EP. Remote results of replacement (survival of endoprosthesis) are directly dependent on the stable primary fixation which is necessary for a bony ingrowth into the porous coating of cementless EP surface to take place. If the acetabular component of endoprosthesis (X-ray measurements are made in A $\mathrm{P}$ or in the front - back projection) is placed in the primary (anatomical) socket of joint, the hip rotation center after surgery practically coincides with the anatomical center of rotation of the joint. If acetabular component is implanted in the secondary socket of the joint, its rotation center is displaced cranially and laterally relative to the anatomical hip socket center of rotation. The choice of acetabular component's localization depends on a number of factors:

- grade of dysplasia; in the current study we used the Crowe classification, it classifies dysplasia into four grades according to the femoral head subluxation;

- $\quad$ type of dysplasia (unilateral or bilateral);

- $\quad$ leg length discrepancy;

- $\quad$ acetabular bone quality (often, significant bone deficiency is present);

- $\quad$ previously conducted operations on replaceable joint.

Most authors believe that it is advisable to position EP's acetabular component in primary or anatomical joint's socket [20-23], thus positioning the hip rotation center at the level of the anatomical joint socket center. According to these authors, the EP's anatomical positioning ensures proper functioning of the gluteal muscles, allowing walking without pronounced limping. Others, like Lund and Harley and co-authors [24, 25] argue that acetabular component of EP can be inserted also into the joint's secondary socket. In very serious cases 
of dysplasia, also Harriss and Bozic and co-authors [26, 27] are of the same opinion. However, virtually no literature sources can be found about the integrated studies of placement of acetabular component of EP (in primary or secondary joint's socket), grade of dysplasia and potential relation of risks of intra- and post-operative complications. DOA is a complex biomechanical problem that affects not only the hip joint. In order to achieve the best possible replacement surgery results, it is necessary to develop precise criteria for the choice of placement of acetabular component of EP.

Survival of primary endoprosthesis is essential not only because it's necessary to return patients back to an active social life (the majority of these patients are of working age) for as long as possible, but also because of the revision operations' significantly higher costs (in comparison with the primary joint replacement).

\subsection{Research aim}

To identify the most suitable placement of acetabular component of endoprosthesis in patients with varying grades of dysplastic osteoarthritis.

\subsection{Research objectives}

1. To implement radiographic analysis (before and after surgery) of patients with dysplastic hip osteoarthritis which had THR in SHTO in years $2008-2011$.

2. To implement functional analysis (before and after surgery) of patients with dysplastic hip osteoarthritis which had THR in SHTO in years 2008 2011.

3. To implement an evaluation of post-operative complications in relation to the placement of acetabular component of endoprosthesis. 
4. To develop an algorithm how to choose the most suitable placement of acetabular component of endoprosthesis in patients with varying grades of dysplastic osteoarthritis.

\subsection{Hypothesis of the research}

Placement of acetabular component of hip endoprosthesis in anatomical localization in patients with varying grades of dysplastic osteoarthritis does not always give the best clinical and functional results.

\subsection{Scientific novelty of the research}

1. Usage of special digital orthopaedic software (AGFA Orthopaedic Tools) for pre-operative planning of location of rotation center of hip endoprosthesis and for analysis of post-operative radiographic results.

2. Developed a method of prognostication of the loosening of the acetabular component of hip endoprosthesis in dysplastic osteoarthritis patients which was awarded Latvian Patent No. 14412 (published on 20.01.2012).

3. Developed algorithm how to determine the most suitable place of acetabular component of hip endoprosthesis during the replacement surgery, depending on the severity of dysplasia.

\subsection{Practical significance of the research}

1. During the replacement surgery, usage of the developed algorithm how to choose the placement of endoprosthesis acetabular component makes it possible to reduce the likelihood of intra- and post-operative complications. 
2. The correct radiographic evaluation of location of EP components provides precise recommendations for further post-operative period as well as for the advisable mode of life and work - thus providing extension of survival of endoprosthesis and distancing of eventual necessity for revision operation.

3. The instrumental gait analysis provided during post-operative period allows evaluating replacement surgery outcomes and facilitating the further development of the rehabilitation plan.

\subsection{Personal contribution}

The author has personally participated in all stages of the research. He has made all the pre- and post-operative radiographic measurements of 106 study THR patients, the patients' functional status assessment and analysis of complications. The author conducted the literature research, analyzed the findings of the scientific work carried out and provided their description. The author personally participated in replacement surgeries of DOA patients either as a surgeon, or as an assistant.

\subsection{Structure of the thesis and its volume}

The thesis is written in Latvian. It has a traditional structure. The document consists of an introduction, literature review, materials and methods review, results, discussion, conclusions, recommendation and bibliography. The thesis is presented on 114 pages. It includes 72 figures and 4 tables. The document refers to the 145 sources. 


\section{MATERIAL AND METHODS}

\subsection{Patients}

The study was conducted in the State hospital of Traumatology and Orthopaedics "Traumatologijas un ortopēdijas slimnīca" (SHTO) and the Gait Analysis Cabinet of National Rehabilitation Center "Vaivari", starting from November $30^{\text {th }}, 2009$, and ending by December $1^{\text {st }}, 2012$. The doctoral thesis research has received consent from the Central Medical Ethics Committee (on November 17, 2009).

Retrospective study included 88 patients with the following hospitalization diagnosis: dysplastic hip osteoarthritis, which underwent 106 total hip replacement operations (for 18 patients - on both sides) in SHTO in 2008 2011. All the patients had given written consent to participate in the study. For all the patients, cementless fixation of hip endoprosthesis was used.

The study did not include patients with other musculo-skeletal apparatus disorders that affect mobility, as well as in patients with decompensated cardiovascular diseases and acute or chronic cerebrovascular disorders. Patients who had received a treatment with endoprosthesis of cement or hybrid type (acetabular component of EP cementless but the stem - cemented) fixation were not included.

Depending on the grade of dysplasia (according to the Crowe classification) and placement of acetabular component of EP during surgery (in joint's primary or secondary socket), 3 groups - one control and two study groups were created. In the control group, were included patients with the hip of grade I or mild dysplasia (by Crowe). Treatment of these patients uses surgery technique which is identical to the one used for the degenerative OA patients. In the patients of the control group, the acetabular component of endoprosthesis was placed in the primary or anatomical joint socket. 
In both study groups, patients having the hip joint with severe dysplasia were included. According to Crowe classification, these patients had grade II, III and IV dysplasias.

\subsubsection{The study groups}

In the first study group (K234P), 34 patients who had acetabular component of EP placed in the joint's primary socket were enrolled, and joints prior to surgery showed grades II, III and IV of dysplasia. 27 patients were females (79.4\%), 7 - males (20.6\%). The average age was 47.09 (33-78) years.

In the second study group (K234S), 25 patients who had acetabular component of EP placed in the secondary joint socket were enrolled, and joints prior to surgery showed grades II, III and IV of dysplasia. 23 patients were females $(92.0 \%), 2$ - males $(8.0 \%)$. The average age was 45.20 (33-78) years.

\subsubsection{The control group}

In the control group (K1), those patients who before surgery were found having the easiest hip dysplasia (grade I according to Crowe classification) were included. Overall, this group included 47 patients. 37 patients were females (78.7\%), 10 - males (21.3\%). The average age was 42.83 (20 - 59) years. In both the control group (47 joints) and two study groups (a total of 59 joints) convincing majority of patients were females. On average, male/female ratio was $4: 1$. 


\subsection{Endoprosthesis used in the study}

In all the operations, only the cementless fixation hip endoprostheses were used. Applied acetabular component models: press-fit: Duraloc, T.O.P., R3, BHR and screwed-in: Zweymuller (Fig. 5, Introduction). Both ceramic and polyethylene acetabular component inserts were used. As EP femoral components (stem of EP), cementless fixation models were applied to the study patients - standard stem of EP (Zweymuller) and short stem (Nanos). External diameters of heads of EP were 28 and $32 \mathrm{~mm}$, they were made of ceramic (Al2O3).

\subsection{Methods}

\subsubsection{Devices used for measurements}

The following measuring instruments were used: a tape-measure and a goniometer. Measuring tape was used to measure both leg length discrepancies (functional shortening of the leg) in millimeters ( $\mathrm{mm}$ ) before surgery. After the operation measurement was repeated - to determine leg length changes. A goniometer was used to measure hip's passive and active ranges of motion: flexion/extension, abduction/adduction and external/internal rotation in degrees $\left({ }^{\circ}\right)$. The measurements were performed before and after surgery.

\subsubsection{The method used in the study to evaluate clinically - functional status of patients}

Functional status of hip was assessed using Merle d'Aubigne and Postel's hip functional status evaluation method [28]. 
This method takes into account three criteria. Pain, potential range of motion and ability to walk (with or without walking aids). Functional status of patient is assessed against each of the scales, and it is placed into one of seven grades or points $(0-6)$. Minimum (worst) grade is 0 which corresponds to recumbent, not-able-to walk patients with severe pain. The maximum total number of points against all three criteria is 18 , which corresponds to a healthy man. Clinical outcomes were assessed before surgery and not earlier than one year after surgery.

\subsubsection{Instrumental gait analysis}

During the period of 1 December, 2011, to 1 March, 2012, in the Gait analysis laboratory of NRC "Vaivari" instrumental gait analysis (IGA) of 28 patients, which, due to DOA, had received 37 total hip replacements in SHTO in the years 2009 and 2010, was performed. During IGA, quantitative information on the individual patient's body segments relative motion during walking was collected.

Video recording of the gait was made simultaneously by 6 infrared digital video cameras that recorded the body mounted markers coordinates and calculated their movement's trajectory. By processing the data with special gait analysis data processing programs, movements of the large joints of all lower limbs during walking were depicted as curves in all three planes simultaneously. Of all the findings, useful data for the research were recorded in a special protocol.

In order to compare the obtained results with normal gait indicators, another control group was established in. This control group included 15 people without musculo-skeletal apparatus diseases or injury consequences that could affect the movement, and who got the IGA. The results were compared with 
instrumental gait analysis data of DOA patients after replacement surgery (IGA was performed not earlier than one year after the surgery).

\subsubsection{Gait deviation index}

For comparison of the results purposes, a gait deviation index was calculated and used. Gait deviation index is calculated based on kinematic data from gait analysis (nine variables): pelvis and hip joint angles in three planes, knee joints in sagittal plane (flexion/extension), ankle joints in sagittal plane (dorsiflexion/plantarflexion) and foot progression angle in Y plane (Fig. 2.1.).

GAITAS CIKLA KINEMATIKA (Laba - sarkana, Kreisa - zala)
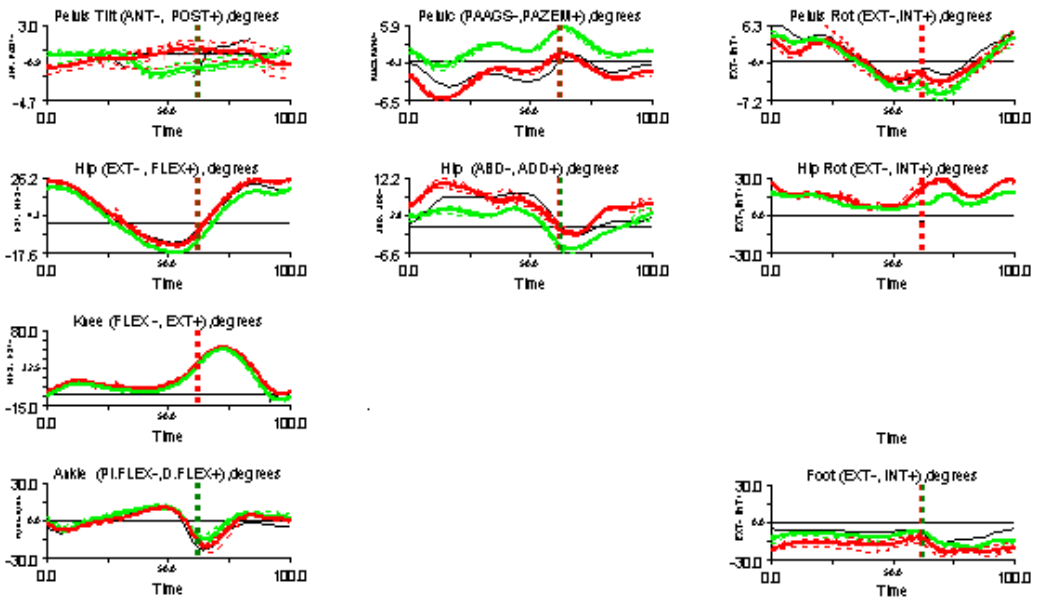

Fig. 2.1. Kinematic data necessary to calculate Gait deviation index

Gait deviation index's value is calculated for the right and left sides of the body separately, and the overall subject gait characteristic is average value of these two indices.

Gait deviation index is a measure which gives a general description of gait abnormality, extent of gait abnormality. The index is used to measure gait, to assess severity of abnormal gait, as well as to assess effectiveness of treatment 
(arthroplasty) and of rehabilitation activities (results). The method provides a single figure which indicates how individual's gait deviates from the average normal model [29].

\subsubsection{Radiographic investigation of DOA patients}

Before surgery, patients had their pelvis A - P (anterior-posterior) and operable hip joint lateral (L - L) radiographically evaluated. The same radiographic investigations were carried out on the third post-operative day, as well as 3 and 12 months after surgery, and later according to the surgeon's discretion - once a year or two years.

Pre- and post-operative radiographic analysis, as well as planning of the placement of components of endoprosthesis and digital programming of its size was performed using orthopedic computer program AGFA Orthopaedic Tools. For calibration of images, marker with diameter of $25 \mathrm{~mm}$ (metallic ball) was used. With the help of phosphorus plates X-ray photographs were obtained in DICOM format and entered into AGFA IMPAX archive. All radiographic measurements were performed twice, thus achieving measurement error being equal or less than $1 \mathrm{~mm}$ or $1^{\circ}$.

To analyze the state of hip joint before and after its replacement, the reference point was set to be the joint's rotation center (RC). Before the operation the center of femoral head is the hip joint's rotation center. After surgery, the center of head of endoprosthesis is the hip rotation center. If the hip joint's RC after surgery (in A - P projection) coincides with the anatomical (primary) acetabular socket's center, it should be regarded that the acetabular component of endoprosthesis is inserted into the primary (anatomical) joint socket. The criterion chosen by us: if the hip joint's RC deviation cranially is less than 10 millimeters, its position also is consistent with the primary acetabular socket. If the hip joint's RC (in A - P projection) after surgery is 
shifted cranially more than $10 \mathrm{~mm}$, we considered that the acetabular component of endoprosthesis is fixed in the secondary socket [30].

To characterize the severity of hip dysplasia we used the Crowe classification (I-IV) [31].

The pre- and post-operative radiographic measurements are performed digitally to the nearest tenth of a millimeter or degree (Figure 2.2., Figure 2.3.).

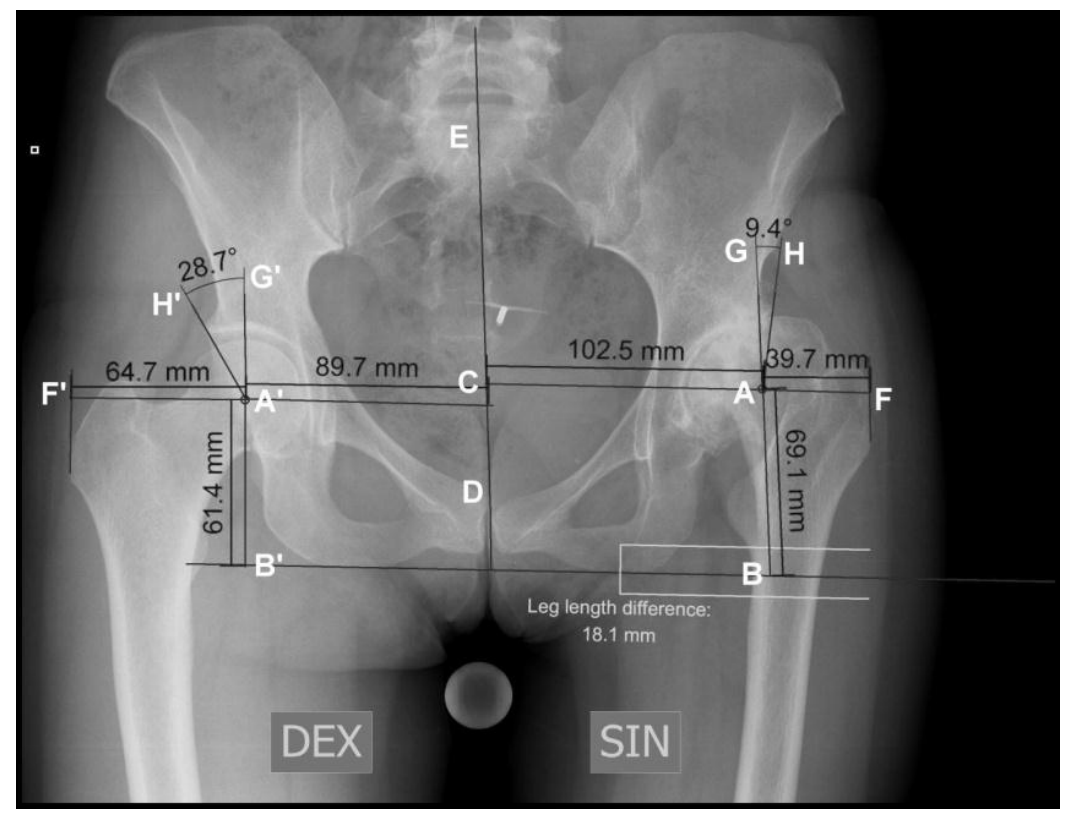

Fig. 2.2 Pre-operative digital radiographic measurements

Vertical location of rotation center of hip (VRC) - segment $\mathrm{AB}(\mathrm{mm})$, the distance between the line connecting the both tuber ischii and the center of femoral head (or heads of endoprosthesis - after surgery). Horizontal location of rotation center of hip (HRC) - AC segment (mm), the distance between the center line (connecting the pubic symphysis and processus spinosus of lumbar spine) and the center of femoral head (or head of endoprosthesis - after surgery). offset - segment AF (mm), the distance between the center of femoral head (or head of endoprosthesis) and the lateral edge of the greater trochanter. Wiberg's lateral center-edge angle (LCEA) angle GAH (in degrees), in case of dysplasia it usually is less than 25 degrees [32] this is the angle between a vertical line drawn from the center of femoral head and the line connecting the center of femoral head with the top lateral edge of the acetabulum. Discrepancy of leg lengths is measured (in $\mathrm{mm}$ ), comparing the distances from the lower edge of minor trochanter (trochanter minus) till the line, connecting both ischial tuberosities. 


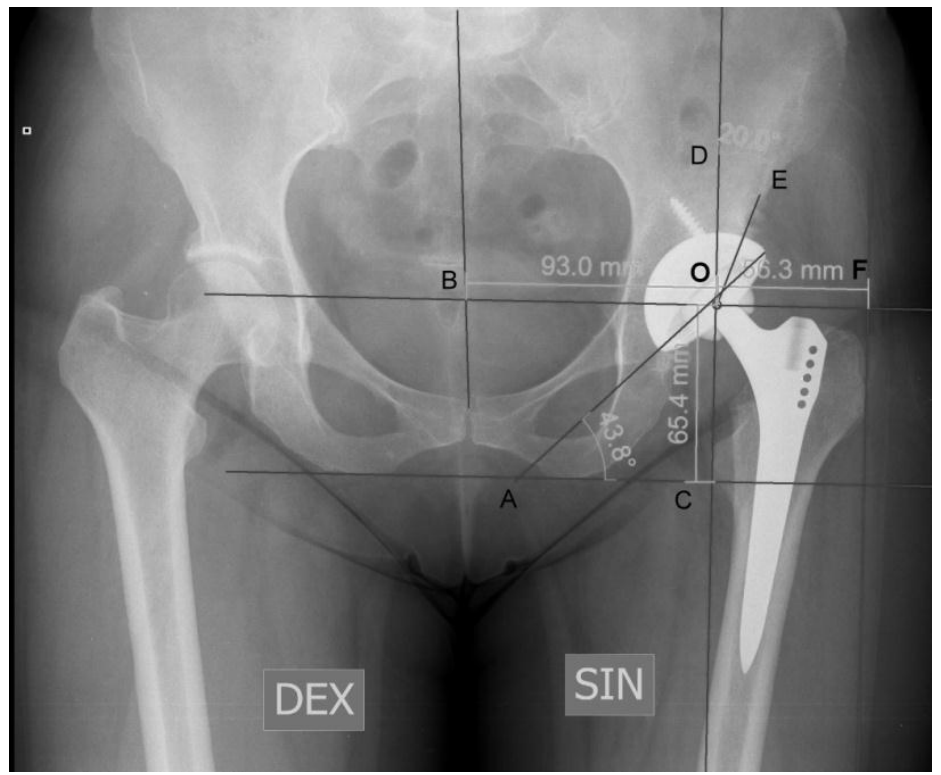

Fig. 2.3. Post-operative digital radiographic measurements

Inclination angle of acetabular component of endoprosthesis in pelvis - angle OAC, vertical location of rotation center of hip (VRC) - segment OC ( $\mathrm{mm})$, horizontal location of rotation center of hip (HRC) - segment BO (mm); offset - segment OF $(\mathrm{mm}) ; C E A$ - angle DOE

The author of this study participated in a development of invention which was awarded Latvian Patent No. 14412. Date of publication of the patent is 20.01.2012. Both authors have invented a specific characteristic for coverage of acetabular component of hip's EP - an angle (CEA or center - edge angle). If after operation (OP) CEA in radiograph's A - P projection is less than $17^{\circ}$, earlier loosening of acetabular component of endoprosthesis can be anticipated.

The proposed technique is non-invasive. One can use this technique to choose further treatment tactics, to draw up a rehabilitation program and to look for recommendations for optimal future lifestyle. 


\subsubsection{Statistical data processing}

The study data processing can be divided into two stages - initial data evaluation and choosing of the statistical hypothesis with the help of different visualization methods, and their subsequent quantitative processing, using testing of statistical hypothesis.

To create the first visual impression of the values of different pre-operative, post-operative main characteristics and interdependencies among them, the work widely exploits different data visualization techniques. This allows to further set statistical hypotheses about value distribution, average value assessments, and correlation between variables.

For the purpose of further quantitative data processing and statistical hypothesis correctness testing, a wide range of methods for statistical hypothesis testing is used (Smirnov - Kolmogorov, ANOVA, Wilcoxon, and Kruskal - Wallis tests).

Data analysis and visualization were performed using SPSS (v. 17.0) statistical data analysis tool. 


\section{RESULTS}

\subsection{Description of the patients set}

The study collected and analyzed data on 88 dysplastic osteoarthritis patients which had undergone 106 primary total hip replacement operations. 70 patients received a single total hip replacement, 18 - both total hip replacements. 71 patients were females (80.7\%), 17 - males (19.3\%). The average age was $44.42(20-78)$ years. Of all the patients, 56 or $63.6 \%$ of the total were working before surgery. Of these, in 80 (75.5\%) cases acetabular component of EP was placed in the primary socket of joint, and in 26 (24.5\%) cases - in the secondary socket.

In the control group (K1), those patients who before surgery were found having the easiest hip dysplasia (grade I according to Crowe classification) were included. Overall, this group included 47 patients. 37 patients were females (78.7\%), 10 - males (21.3\%). The average age was 42.83 (20 - 59) years.

In the first study group (K234P), 34 patients who had acetabular component of EP placed in the primary joint socket, and whose joints prior to surgery showed grades II, III and IV of dysplasia, were enrolled. 27 patients were females (79.4\%), 7 - males (20.6\%). The average age was 47.09 (33-78) years.

In the second study group (K234S), 25 patients who had acetabular component of EP placed in the secondary joint socket, and whose joints prior to surgery showed grades II, III and IV of dysplasia, were enrolled. 23 patients were females $(92.0 \%), 2$ - males $(8.0 \%)$. The average age was $45.20(33-78)$ years.

Hip joints of 41 patients had a history of surgeries, the most frequent ones were - open repositions during childhood (17 cases) and corrective osteotomy of the proximal femor with a purpose to achieve more complete femoral head's 
coverage in the joint's socket ( 24 cases). The control group had a history of operations carried out in 16 cases (34.0\%), the first study group - 13 cases (38.2\%), and the second study group -12 cases $(48.0 \%)$.

Distribution of patients according to grades of dysplasia (Crowe classification) in both study groups and in the control group (Fig. 3.1.).

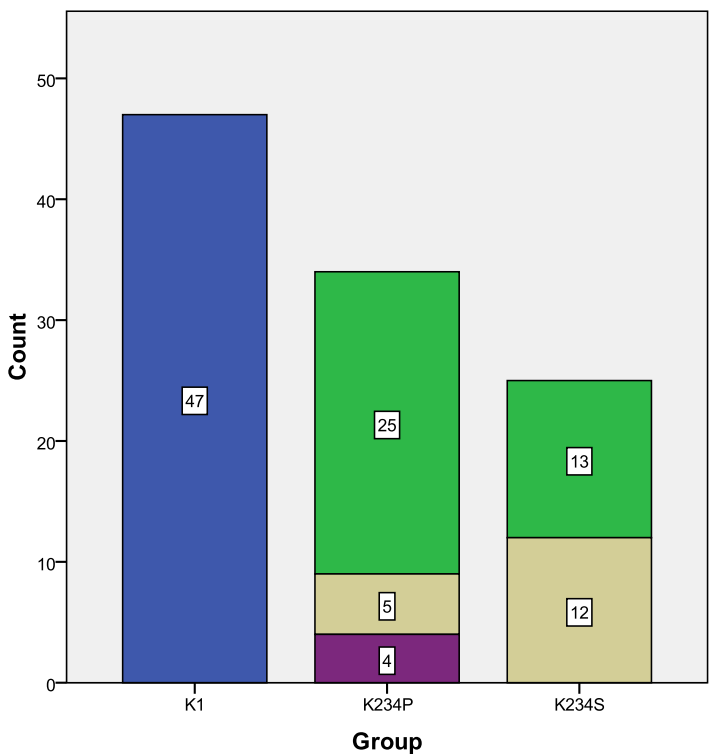

Grade of dysplasia

品II
骂

Figure 3.1. Distribution of patients according to grade of dysplasia in each group

\subsection{Radiographic imaging results}

EP acetabular component's center - edge angle (CEA) after OP averaged $28.27^{\circ}$. Comparing this angle with the Wiberg's LCEA before OP $\left(13.75^{\circ}\right)$, we can judge what the EP acetabular component's coverage by bone is after OP in relation to the femoral head's coverage before OP. Average coverage (relative to the hip joint's rotation center) has increased by $14.52^{\circ}$. 
To assess whether the increase of CEA after OP is statistically significant, CEA average value t-test was performed before and after OP. Test results showed a statistically significant $(\mathrm{p}<0.001)$ CEA average value's increase after OP (Fig. 3.2.).

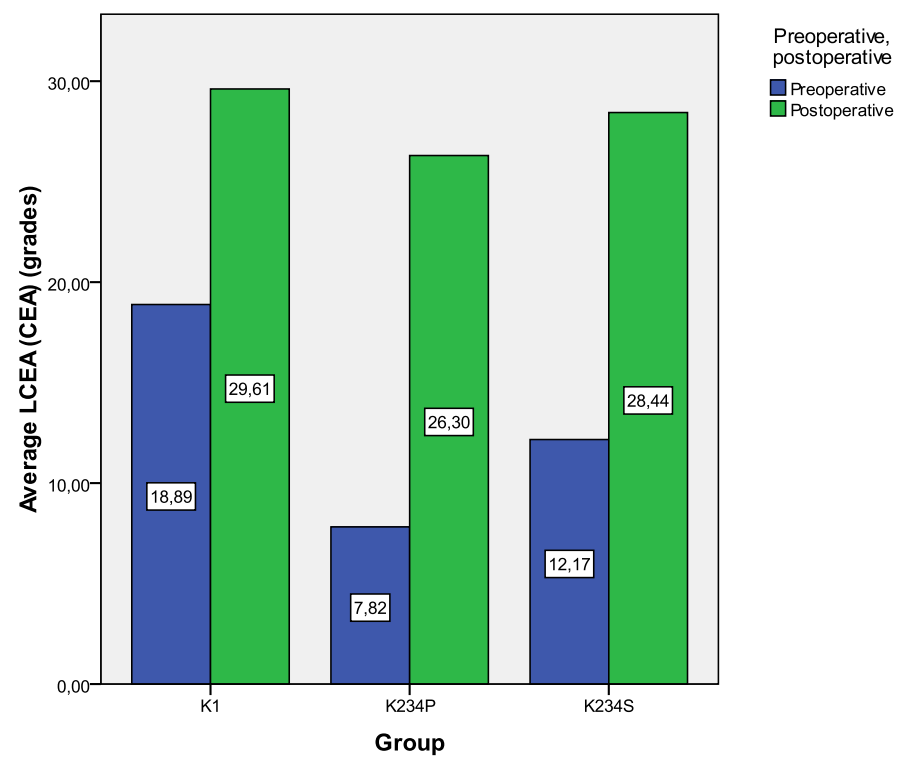

Figure 3.2. Lateral center - edge angle (LCEA) change (pre- and past-operative in control group and in both study groups

To assess whether the average value of LCEA before surgery is statistically significantly different in the control group and both study groups, standard ANOVA test was performed (LCEA being a normally distributed parameter). The results show that LCEA average value differences between groups are statistically significant $(\mathrm{p}=0.001)$. In addition, an in-depth analysis shows that statistically significant differences in LCEA average values are between the control group and the first study group $(\mathrm{p}<0.001)$ and between the control group and the second study group $(\mathrm{p}=0.038)$. 
Like in the previous case, to assess whether the average value of LCEA before surgery is statistically significantly different in the control group and both study groups, standard ANOVA test was performed (LCEA being a normally distributed parameter). The results show that CEA average value differences between groups were not statistically significant $(\mathrm{p}=0.186)$.

To assess whether the reduction of HRC location after OP is statistically significant, HRC location average value t-test was performed before and after OP. Test results showed a statistically significant ( $\mathrm{p}<0.001)$ HRC average value's decrease after OP (Fig. 3.3.).

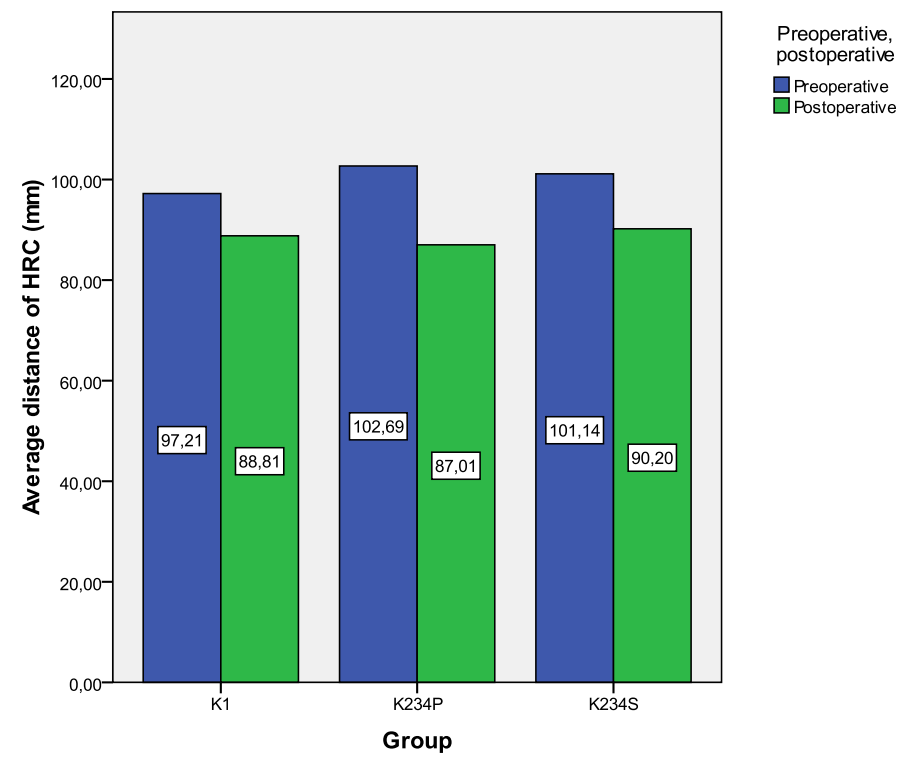

Figure 3.3. Average location of horizontal rotation center of hip (HRC) in the control and in both study groups (pre-and post-operative)

In the control group (K1), average hip rotation center vertical (VRC) location before OP was $59.68 \mathrm{~mm}$. After OP, VRC location averaged 63.04 $\mathrm{mm}$. In the first study group (K234P), average VRC location before OP was $64.55 \mathrm{~mm}$. After OP, VRC position averaged $61.45 \mathrm{~mm}$. In the second study 
group (K234S), average VRC position before OP was $66.23 \mathrm{~mm}$. After OP, VRC position averaged $69.60 \mathrm{~mm}$ (Fig. 3.4.).

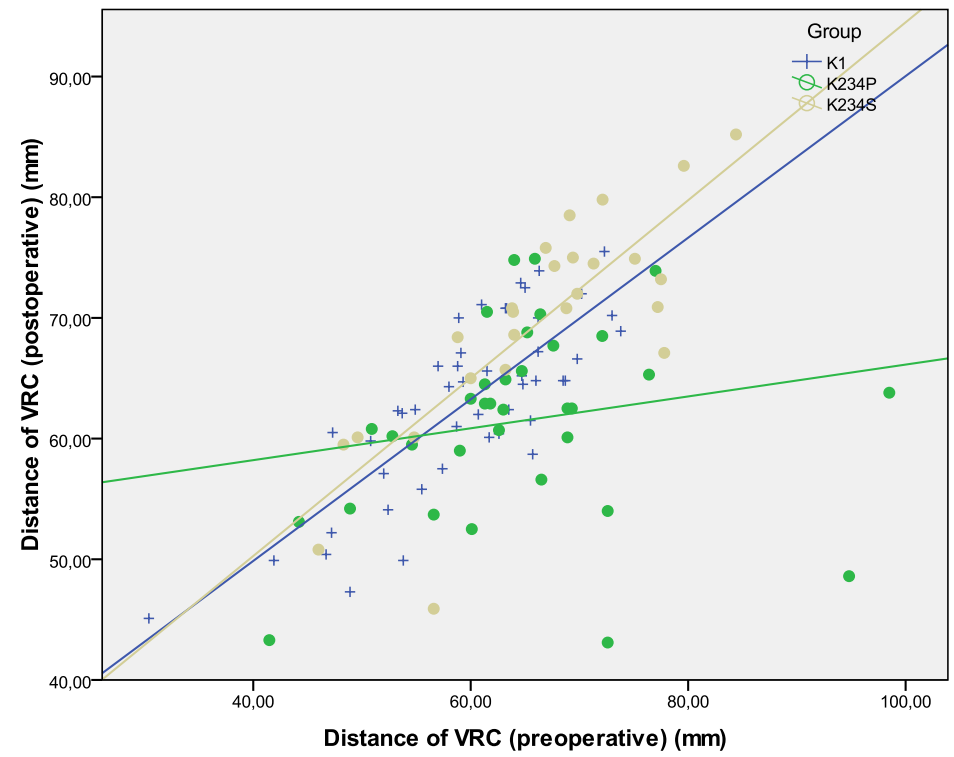

Figure 3.4. Vertical location (distance) of rotation center of hip joint (VRC) in the control and in both study groups (pre-and post-operative)

To assess whether the average location (distance) of VRC before surgery is statistically significantly different in the control group and both study groups, standard ANOVA test was performed (VRC location value being a normally distributed parameter). The results show that VRC locations' average value differences between groups are statistically significant $(\mathrm{p}=0.016)$. In addition, an in-depth analysis shows that statistically significant differences in VRC locations' average values are between the control group and the first study group ( $\mathrm{p}=0.033$ ) and between the control group and the second study group $(\mathrm{p}=0.009)$.

Like in the previous case, to assess whether the average value of VRC location after surgery is statistically significantly different in the control group 
and both study groups, standard ANOVA test was performed (VRC location value being a normally distributed parameter). The results show that VRC locations' average value differences between groups are statistically significant $(\mathrm{p}<0.001)$. An in-depth analysis shows that statistically significant differences in VRC locations' average values are between the control group and the second study group $(\mathrm{p}=0.001)$, and between both study groups $(\mathrm{p}<0.001)$.

Offset (the distance from the hip joint rotation center till the lateral edge of the trochanter majus) after OP on average was $62.06 \mathrm{~mm}$. Compared to the values before $\mathrm{OP}$, offset has increased by $12.63 \mathrm{~mm}$. T-test results showed that the average offset value increase was statistically significant $(\mathrm{p}<0.001)$.

On average, EP acetabular component's inclination angle in pelvis was $40.96^{\circ}$. In the control group (K1), it was $40.83^{\circ}$, in the first study group (K234P) $-41.86^{\circ}$, in the second study group (K234S) - 39.99 .

The average EP acetabular component's size (outer diameter) was 52.95 $\mathrm{mm}(46-64 \mathrm{~mm})$. In the control group (K1), it was $53.23 \mathrm{~mm}$, in the first study group (K234P) $-53.03 \mathrm{~mm}$, in the second study group (K234S) -52.32 $\mathrm{mm}$.

Average anatomical leg length discrepancy before surgery was $10.16 \mathrm{~mm}$ after the operation $-3.56 \mathrm{~mm}$. To evaluate the OP's effect on pre-operative and post-operative anatomical leg length discrepancy, non-parametric Wilcoxon pairs test (post-operative anatomical leg length discrepancy is not a normally distributed parameter) was performed. The obtained test results show a statistically significant $(\mathrm{p}<0.001)$ changes (post-operative anatomical leg length discrepancy measurements tend to be smaller than the pre-operative ones). 


\subsection{DOA patients' clinical-functional results}

\subsubsection{Grading by Merle-d'Aubigne-Postel method}

Pre- and post-operative functional results of patients are showed in Figure 3.5 .

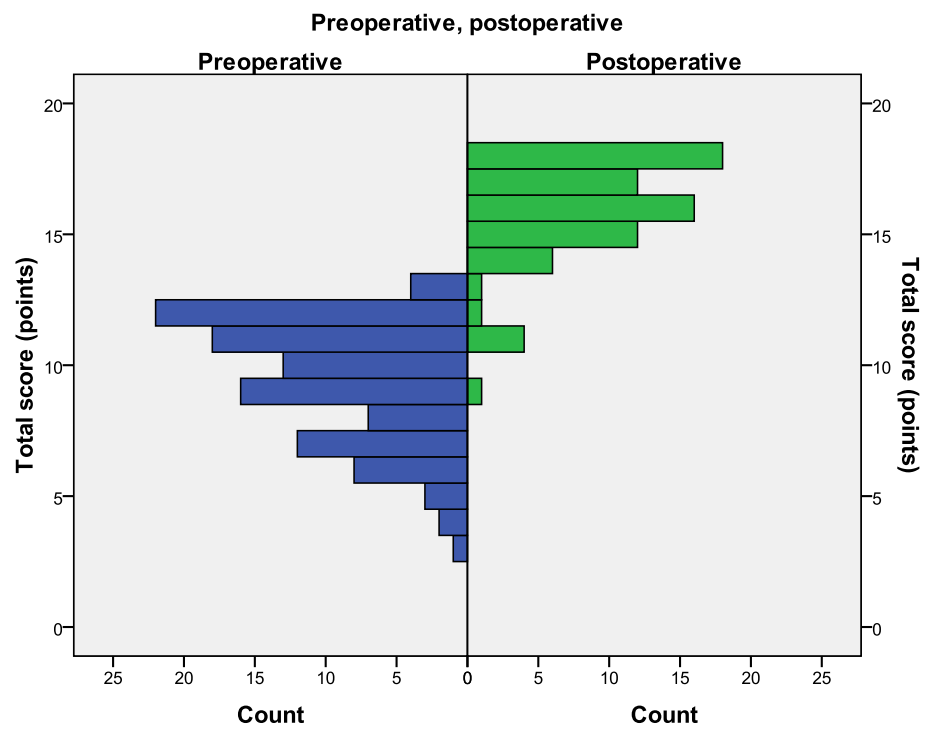

Figure 3.5. Overall functional assessment of patients before and after surgery (by Merle d'Aubigne and Postel method)

To statistically evaluate the effect of OP on preoperative and postoperative assessments against all of the scales, parametric Wilcoxon pairs test (preoperative and post-operative assessments in no one of the scales are normally distributed) were conducted. The obtained test results for all of the scales demonstrated a statistically significant $(\mathrm{p}<0.001)$ OP's positive effect. 
Average total functional evaluation points for different grades of dysplasia patients (both control and study groups) before/after surgery can be seen in Table 3.1.

Table 3.1.

Method of Grading Functional Value of Hip-Merle d'Aubigne and Postel

\begin{tabular}{|l|c|r|r|c|}
\hline \multirow{2}{*}{$\begin{array}{c}\text { Merle d'Aubigne and Postel } \\
\text { scales }\end{array}$} & \multicolumn{5}{|c|}{ Grade of dysplasia (Crowe classification) } \\
\cline { 2 - 5 } & I & \multicolumn{1}{|c|}{ II } & \multicolumn{1}{c|}{ III } & IV \\
\hline \multicolumn{5}{|c|}{ Before surgery } \\
\hline Pain scale & 1,85 & 1,68 & 1,35 & 1,50 \\
\hline Movement Scale & 4,02 & 4,08 & 4,00 & 4,50 \\
\hline "Ability to walk" scale & 4,04 & 3,76 & 2,71 & 3,25 \\
\hline Total (points) & $\mathbf{9 , 9 1}$ & $\mathbf{9 , 5 3}$ & $\mathbf{8 , 0 6}$ & $\mathbf{9 , 2 5}$ \\
\hline \multicolumn{6}{|c|}{ After operation } \\
\hline Pain scale & 5,16 & 5,29 & 5,60 & 5,00 \\
\hline Movement Scale & 5,26 & 5,48 & 5,53 & 4,75 \\
\hline "Ability to walk" scale & 5,23 & 5,48 & 5,00 & 4,75 \\
\hline Total (points) & $\mathbf{1 5 , 6 5}$ & $\mathbf{1 6 , 2 4}$ & $\mathbf{1 6 , 1 3}$ & $\mathbf{1 4 , 5 0}$ \\
\hline
\end{tabular}

Applying Kruskal-Wallis test on post-operative assessments in all scales, it shows that the assessments in groups with different grades of dysplasia are relatively homogeneous ( $\mathrm{p} \geq 0.228$ ) and no statistically significant differences between groups (Figure 3.6.) are observed. 


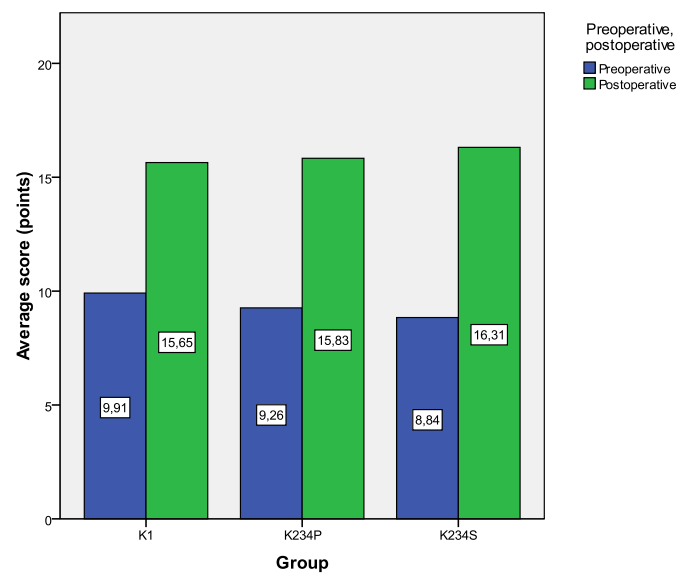

Figure 3.6. Overall functional assessment of patients before and after surgery (by Merle d'Aubigne and Postel method) in the control group and both study groups

\subsubsection{Instrumental gait analysis}

IGA was performed for 28 patients ( 22 females, 6 males) who had 37 total hip replacements (9 patients - both hips) due to dysplastic osteoarthritis. The average age of patients was $46.6(28-63)$ years.

Joints' (IGA records) distribution among the groups was the following: in the control group (K1) - patients with grade I (mild) dysplasia by Crowe - 17 joints, in the first study group (K234P) - patients with grade II, III, IV (severe) dysplasia with acetabular component of EP placed in the primary joint socket 12 joints, in the second study group (K234S) - patients with grade II, III, IV (severe) dysplasia with acetabular component of EP placed in the secondary joint socket - 8 joints. In addition, one more control group (K0), which included 15 healthy, non-operated people without musculo-skeletal apparatus diseases, was formed. In this group, there were 9 females and 6 males. The average age of the group was $61.2(41-73)$ years. Instrumented gait analysis was 
performed on both body sides thus IGA records of 30 hip joints of the group K0 were analyzed in total.

IGA showed a difference in the support and swing phase durations. In a year or more after replacement, the average values of parameters over all replaced joints (of study patients) were compared with gait analysis parameters of non-operated people having no musculo-skeletal diseases (control group). In the study (subjects who had replaced hips) group, average value of support phase was longer, and it amounted to $64.18 \%$ of the gait cycle time versus $62.13 \%$ in the control group (healthy subjects) group. Swing phase, conversely, was longer in the control group (37.87\%, versus $35.82 \%$ of the study group). In swing phase of the study group, hip motion total range in the sagittal plane was $30.47^{\circ}$, in the control group $-39.78^{\circ}$. The maximal values of hip flexion and extension in the sagittal plane in swing phase, were different too. In the study group, maximal flexion (average value) was $34.51^{\circ}$, in the control group $30.47^{\circ}$. Conversely, at the end of support phase the control group had a maximum extension of $8.32^{\circ}$, but the study group $-4.04^{\circ}$ (so, the hip joint stayed in flexion, not reaching the extension position at all). Range of motion of pelvis (in sagittal plane) of THR patients (average) was $5.38^{\circ}$, compared to $2.69^{\circ}$ in the control group. Minimum flexion (maximum extension) in support phase of knee joint of THR patients was $9.8^{\circ} \pm 8.6^{\circ}$, and of the non-operated individuals (control) $-6.4^{\circ} \pm 5.7^{\circ}$. Also, support reactions data did not show statistically significant differences: the hip abduction moment of the replaced joints was $0.51 \mathrm{Nm} / \mathrm{kg}$ against $0.63 \mathrm{Nm} / \mathrm{kg}$ - in the healthy people group.

Gait deviation index (GDI) average values in different groups are showed in Figure 3.7. 


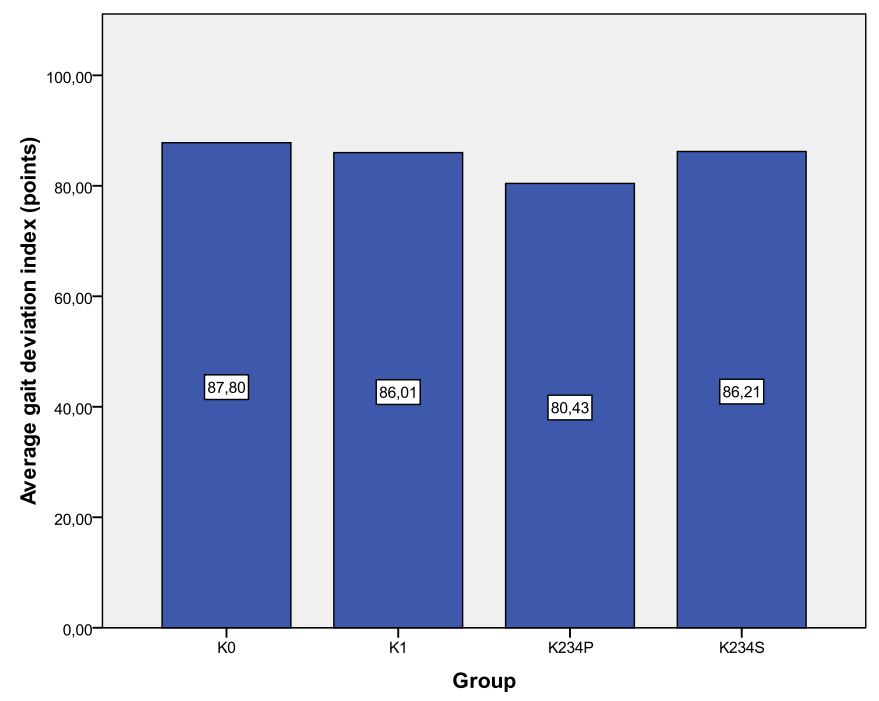

Figure 3.7. Patient GDI figures in each of the investigated groups

To assess whether gait deviation index's (GDI) average values are statistically significantly different across groups, a standard ANOVA test (GDI is a normally distributed parameter) was performed. The results show that gait deviation index (GDI) average values difference between groups is not statistically significant $(\mathrm{p}=0.235)$ (or, the current amount of data is not sufficient to demonstrate the opposite).

\subsection{Complications}

The study analyzed the major complications or those complications that had an impact on the patient's rehabilitation time and later quality of life. Number of such complications constituted $9.43 \%$ of all the total hip replacement cases (106). Breakdown of the complications: 7 bone fractures, 2 nerve damages, and 
one case with pronounced resorption (osteolysis) of the proximal femor after fracture osteosynthesis with cerclage wiring at the primary THR.

Nine of the complications were detected early (within the first 6 weeks after surgery), one (osteolysis) - late (4 years after replacement OP). In that case, it was necessary to carry out revision OP. All the complications were detected when the acetabular component of EP was positioned in the joint's primary socket. In all 7 cases, patients with complications associated with bone fractures ( 6 femoral fractures and 1 sciatic bone fracture) before surgery was found having high-grade dysplasia (study group K234P) - grades III ( 2 cases) and IV ( 5 cases) by Crowe. In 5 cases of these patients, history of previous treatment already included operations on replaceable joint. During primary THR 4 fractures of proximal femor were found. In each of these cases, the range of operation was increased, and the femoral osteosynthesis with cerclage wiring (Figures 3.8., 3.9.) was performed.

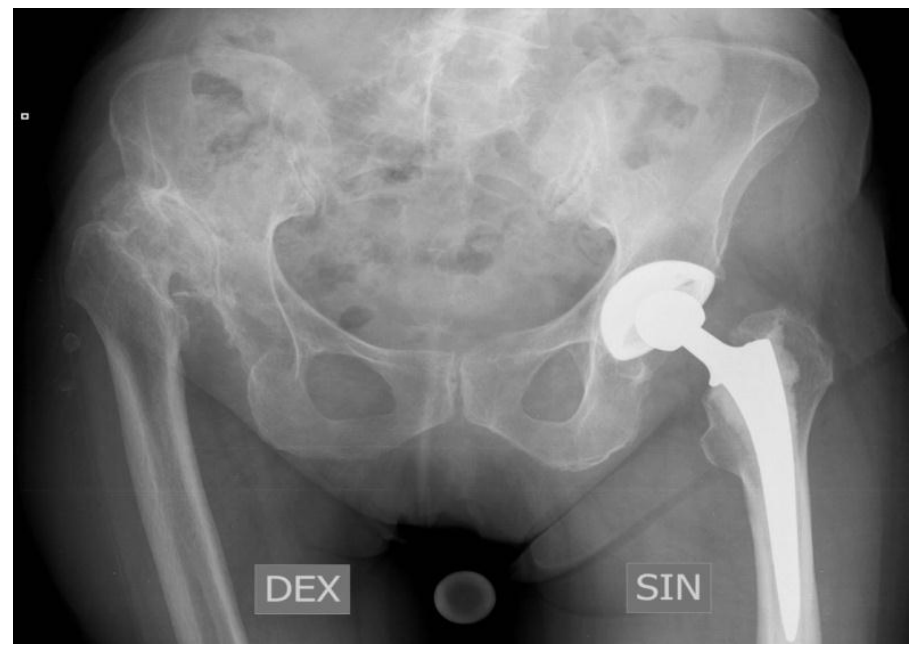

Figure 3.8. DOA of right hip joint (grade IV dysplasia by Crowe) 


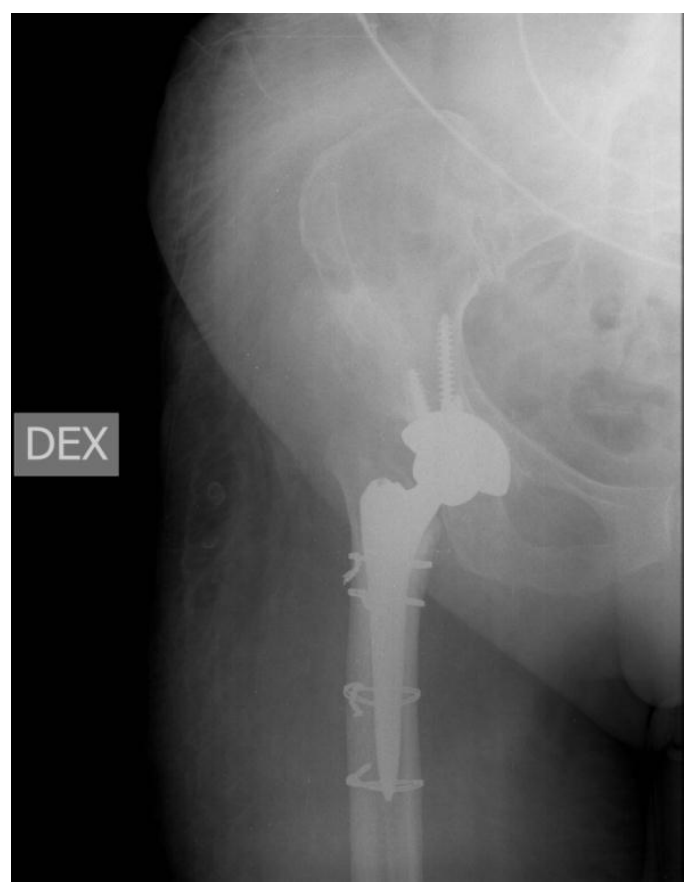

Figure 3.9. Complication: fracture of proximal femur during THR of the right hip joint (acetabular component of EP placed at the anatomical localization)

In both nerve damage cases, patients were from the control group (KI), having grade I dysplasia. In one case (which compounded with n.ischiadicus damage), the leg during surgery was elongated by 4 centimeters, in addition, the treatment history of this patient already had 2 surgeries in the replaceable joint.

In the control group (K1), there were complications in two cases (4.3\%); in the first study group, where acetabular component of EP was placed in the joint's primary socket (group K234P) - 8 cases (17.6\%), while the second study group, where acetabular component of EP was placed in the joint's secondary socket (group K234S), - none (0.0\%) (Figure 3.10.). 


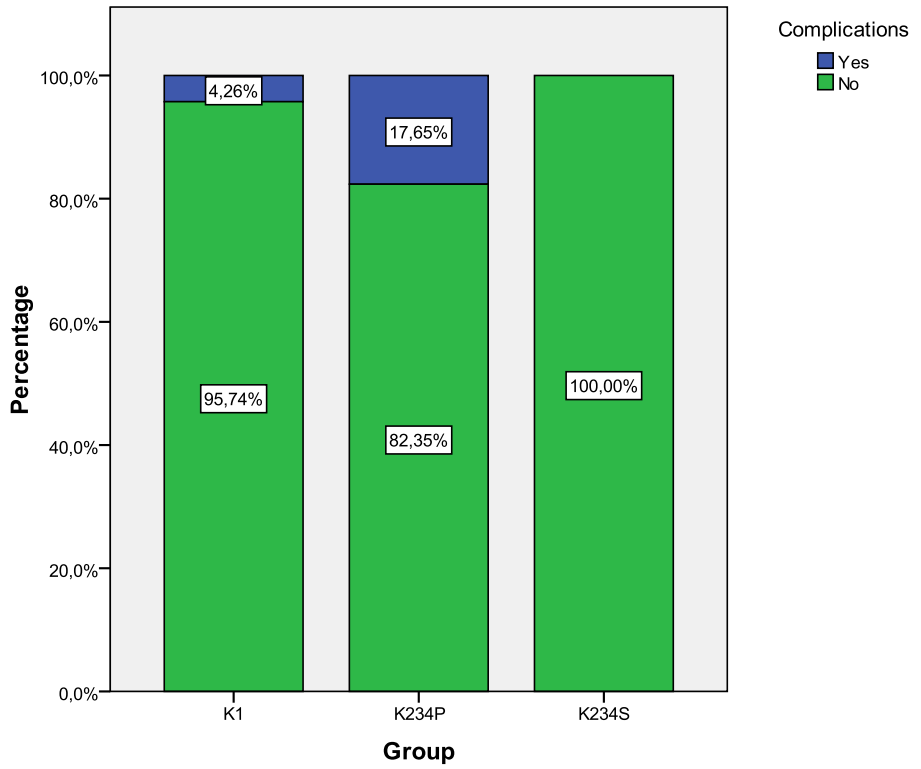

Figure 3.10. Distribution of complicated/uncomplicated replacement percentages in control group and both study groups

With a purpose of assessing whether using various pre-operative measurements it is possible to assess the risk of post-operative complications, all 106 replaced joints were arbitrarily divided into two groups: "With complications" (10 patients in group) and "No complications" (96 patients in group).

In the group, which had complications detected after replacement OP, in $62.5 \%$ of cases there was a history of previous surgery performed, while in the group without complications - in $36.7 \%$ of cases.

To assess whether the average value of LCEA before surgery is statistically significantly different in the "With complications" group and "No complications" group, standard ANOVA test was performed (LCEA is a normally distributed parameter). The results show that the average value of LCEA in the group "With complications" is less than the average value of 
LCEA in the group "No complications", and, furthermore, the obtained result is statistically significant ( $\mathrm{p}=0.032)$ (Fig. 3.11.).

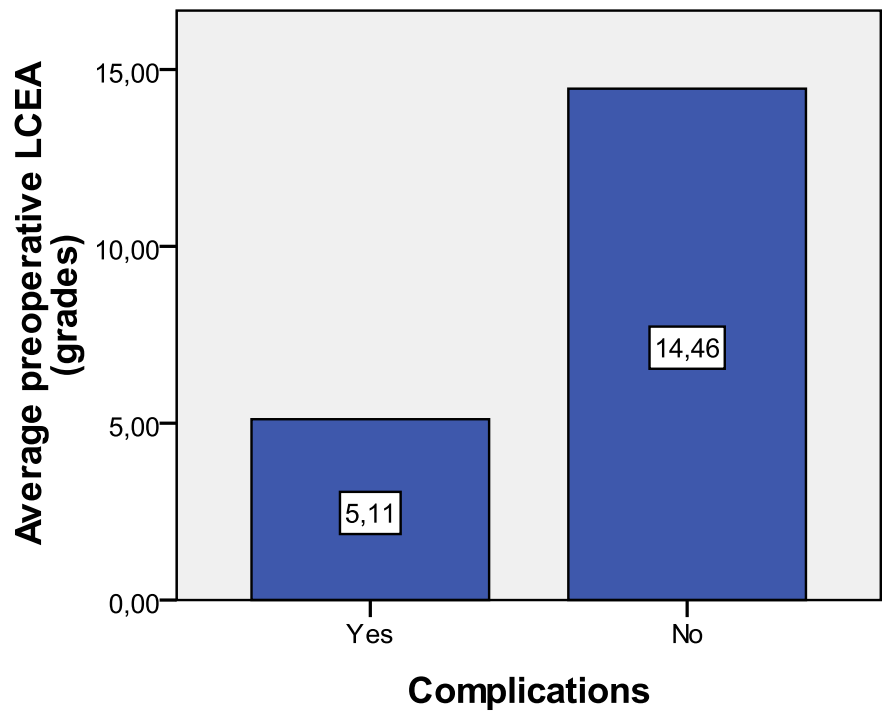

Figure 3.11. The average pre-operative LCEA in replaced joints with complications ("With complications") and without complications ("No complications")

To assess whether the average values of offset, HRC and VRC before surgery are statistically significantly different in the "With complications" group and "No complications" group, standard ANOVA test was performed (offset, HRC and VRC are normally distributed parameters). The results show that differences between both groups of average values of all these parameters are statistically significant $(\mathrm{p}<0.001)$. 


\section{DISCUSSION}

In our research, patient age (average 44.42 years) and gender $(80.7 \%$ female, $19.3 \%$ male) structure coincides with a similar trend as in most literature sources $[32,33,34]$. It is essential that patients are of working age. Despite the onset of illness, $63.6 \%$ of patients in our study were working before surgery. Therefore, we believe it is important to apply the operations methodology that would allow patients to return to work as quickly as possible.

\subsection{Analysis of the radiographic results}

An important role in the analysis of the radiographic results plays special orthopaedic software - AGFA Orthopaedic Tools. X-ray calibration makes it possible to make accurate measurements before and after surgery, as well as to perform computer-based pre-operative planning. In order to assess the position of the hip joint in pelvis (before OP) and placement of the EP (after OP), the reference point was the joint's rotation center $(\mathrm{RC})$. Before OP it coincides with the center of the femoral head, after the OP - with the center of EP's head.

In order to characterize the femoral head coverage by bone before replacement, we used Wiberg's lateral center - edge angle (LCEA). This parameter also characterizes the hip dysplasia severity. Wiberg believed if LCEA is less than $20^{\circ}$ that indicates pathology, namely, dysplasia. In our study group $\mathrm{K} 1$, LCEA was $18.89^{\circ}$, in group K234P - 7.82 ${ }^{\circ}$, and in group K234S $12.17^{\circ}$. Statistical analysis indicated that there are significant differences in LCEA average values between the control group and the first study group $(\mathrm{p}<0.001)$, or between the control group and the second study group $(\mathrm{p}=0.038)$. The greater is grade of dysplasia, the less is LCEA, and femoral heads coverage also is smaller. For the K234P group, it also justifies the placement of EP - in the primary socket. 
Also, sufficient coverage by bone of the acetabular component of EP after surgery is essential to achieve a stable primary fixation of the EP. Author has developed a method of prognostication of the loosening of the acetabular component of hip endoprosthesis. The measurement of the center - edge angle (CEA) is performed which characterizes the acetabular component of EP coverage by bone. Both Wiberg's LCEA and CEA are comparable characteristics because they characterize the femoral head's (before OP) and the acetabular component of EP (after OP) coverage by bone, and both are measured from the joint's rotation center. If CEA after OP is $<17^{\circ}$, the author predicts elevated risk of loosening of acetabular component of EP. Patients, who after OP have hip $\mathrm{CEA}<17^{\circ}$, need a special rehabilitation program which includes both a longer walking with crutches (up to 12 weeks), semi-loading the operated leg and specific recommendations for future life and work arrangements.

Hip position is characterized by the position of the horizontal the rotation center (HRC) or its distance from the midline of the body and the position of vertical rotation center (VRC) or its distance from the line joining both ischial tuberosities (tuber ischia). Before the OP, due to the fact that the femoral head has migrated in cranio - lateral direction, both the HRC and VRC values are higher than on the contralateral side (with the condition that it is healthy).

The horizontal rotation center (HRC) location showed statistically significant $(\mathrm{p}<0.001)$ change (reduction) after surgery, at both the control and two study groups. This is due to the need for medialization of acetabular component of EP during the operation to ensure that it has sufficient coverage by bone. Thus, the HRC position (distance from the center line) decreases.

Differences of average VRC position values between the different groups before OP are statistically significant $(\mathrm{p}<0.001)$. They depend on the grade of dysplasia - the more sever it is, the greater is VRC position's distance. During the replacement, when acetabular component of EP is placed in the joint's 
primary socket, rotation center is shifted distally - it explains also the VRC post-operative position's average values reduction in the study group K234P.

At grade I, II, III dysplasias average VRC position's value appreciation is associated also with the specifics of pelvis anatomy of DOA patients. Acetabulum is oval, oblong (in cranially - caudal direction). In order to achieve the most complete acetabular component of EP coverage by bone ("roof"), the joint's rotation center should be moved not only medially but also cranially. If it is kept at the VRC pre-operative level position, then, inserting the spherical acetabular component of EP, may cause the deficit of acetabulum 's "roof" part (insufficient EP's coverage by bone). In these cases, the bone defect site has to be filled with bone graft. In our study, in five cases the acetabulum bone loss was compensated (substituted) with autobone from the patient's femoral head, fixing it to pelvis by osteosynthesis screws.

Also, statistically significant was offset (distance from the hip joint center to the lateral edge of the trochanter major) value variation before and after surgery $(\mathrm{p}<0.001)$. In DOA patients before the OP, due to abnormal anatomy (femoral neck anteverted and in valgus position), offset is generally reduced compared with healthy joints. As a result, arm of abductor muscle force is reduced, and that leads to abductor weakness with gait changes. Offset's increase that is important for the stability of joint and the normal operation of muscles is achieved through the usage of EP stems with industrially embedded normal femoral neck - shaft angle (usually between $126^{\circ}$ and $135^{\circ}$ ). If necessary, the offset can be increased with the help of modular EP heads with different neck segment sizes.

\subsection{Analysis of the functional results}

According to Merle-d'Aubigne-Postel hip functional status assessment method, the worst scores before surgery (in 6-point scale, where "0 points" is 
the lowest possible assessment) was exactly on the pain scale - an average of 1.7 points ("0 points" - an intense, strong pain, "6 points" - no pain). There is also a rationale - the main indication for surgical treatment (joint replacement) is pain. In addition, low pre-operative assessment on pain scale was both in control and study groups. Average scores on "movement" (4.06 points) and "ability to walk" (3.70 points) scales in comparison to the pain scale scores (1.7 points) were significantly improved which indicates about high adaptability during lifetime of these relatively young patients and about compensatory abilities of body. Comparing functional results of the control group K1 and two study groups of patients, it could be concluded that there were no significant differences between groups after operation $(\mathrm{p} \geq 0.228)$. The overall result was close to the healthy person's characteristics; furthermore, in the group which had acetabular component of EP placed in the joint's secondary socket (K234S) it was even slightly higher than in the other two groups (K1 and K234P) which had acetabular component placed in the primary socket.

In assessment of replacement surgery's functional result, important was instrumental gait analysis (IGA). Overall, gait and range of motion in joints after the replacement and one year of rehabilitation in both the control and two study groups was close to a healthy person's gait parameters. The differences can be explained by the remaining pre-operative gait stereotype and compensator mechanisms developed during lifetime. For example, total hip range of motion in swing phase in DOA patients after THR remains below the healthy person's range of motion $\left(30.47^{\circ}\right.$ against $39.78^{\circ}$, however, the range of movement of the pelvis, conversely, is higher than normal. It would therefore seem that pelvic motions are compensating the reduction of range of hip motions.

In order to characterize the gait changes numerically, we used a gait deviation index (GDI)). Interestingly, the GDI was higher for patients with EP inserted into the joint's secondary socket $(\mathrm{GDI}=86.15)$ than for patients with 
EP's position in the primary socket (GDI=83.14). For comparison - a healthy (control group - persons without support musculo-skeletal apparatus disorders) persons' GDI was 87.80 . For these figures to become statistically significant there is a need for a larger number of observations.

\subsection{Analysis of functional leg length difference}

In literature sources, discussion continues as to whether leg length difference affects post-operative clinical result. The results of research are controversial. Konyves and Bannister [35] concluded that if the operated leg after the operation is longer, the functional result is worse than for patients with equal leg length. Conversely, White and Dougall [36] have shown that there is no statistically significant correlation between leg length difference and patient satisfaction level and functional result.

Our study did not reveal any direct leg's functional length correlation with anatomical elongation of leg during surgery. Performing measurements a year or more after the replacement, it is evident that for some of patients body compensatory mechanisms, developed during lifetime, keep working after surgery which try to correct leg length discrepancy and pre-operative restrictions of movement by the pelvic tilt and hypermobility, and curved lumbo - sacral region of spine. For some patients, these countervailing mechanisms had become irreversible (structural). In these patients, the old (presurgery) motion stereotypes keep running and, by redressing the anatomical limb length, a functional elongation of leg can be achieved.

\subsection{Analysis of complications}

The absolute majority of authors stresses that the risk of complications for dysplastic osteoarthritis patients with replaced hip is significantly higher than for primary osteoarthritis patients $[18,37]$. Complications are mainly due to 
greatly altered hip anatomy [38], especially in patients with grade II, III, IV dysplasia (by Crowe classification).

The radical anatomical - biomechanical reconstruction of the hip joint made during THR can cause not only local complications, like $n$. ischiadicus traction type damage with the foot paresis [39], without tenotomy hard to correct flexion contracture in hip joint, fracture of proximal femor during surgery, early loosening of acetabular component, etc., but also - a general musculo-skeletal apparatus distress phenomena.

After hip surgery, patients may experience pain, discomfort in back and other joints. When planning the placement of endoprosthesis component, one must be able to balance their anatomical positioning flexibility with risk of potential complications.

One of the most common complications following THR in patients with dysplastic coxarthrosis is the endoprosthesis head dislocations [17]. None of our study patients which had been operated (observation period 12-52 months) experienced the EP dislocations. The operations were performed using endoprosthesis heads which were of 28 and $32 \mathrm{~mm}$ diameters. In order to minimize the early (up to 6 weeks after surgery) risk of dislocation, we used acetabular components which had an anti-luxation mechanism incorporated (Duraloc, R3, T.O.P., Bicon models). Polyethylene inserts of EP's acetabular component with anti-luxation rim ("lip") were applied, thus increasing the endoprosthesis head's coverage by 10 or 20 degrees and reducing the risk of dislocation of the EP head. Using the polyethylene insert with a "lip", the acetabular component can also be positioned more vertically (inclination angle in pelvis up to 55 degrees), thus achieving greater EP contact surface with a bone and more stable primary fixation in pelvis. However, in a longer period of time, the more vertical position of EP's acetabular component might cause faster wear of polyethylene insert due to its uneven load, which can also manifest itself with a late complication - EP head dislocation. Similarly, 
polyethylene wear particles migrate and get between the endoprosthesis and bone, enhancing cystic-degenerative changes (osteolysis). It may result in EP components' late aseptic loosening and, in lingering (untreated) cases, even in femoral periprosthetic fractures.

Meanwhile, the artificial joint socket's insufficient coverage by bone may cause aseptic loosening of EP. Acetabular component's sufficient coverage by bone is very important for survival of EP. In literature sources, most authors agreed that it is permissible to have around $30 \%$ of the acetabular component of EP uncovered by bone [40, 41]. The author of the current study invented the original measure of EP acetabular component's coverage - angle (CEA), which was patented in Latvia. In order to provide a stable primary fixation of EP, CEA should be $>17^{\circ}$. Avoiding endoprosthesis component malposition (acetabular component's inclination angle in the pelvis $>55^{\circ}$ or $<35^{\circ}$, anteversion $>25^{\circ}$ or $<0^{\circ}, \mathrm{CEA}<17^{\circ}$ ), and through the soft tissue sparing surgery technique one can significantly reduce the EP loosening and risk of luxation, and polyethylene wear.

Part of the authors [42] has shown that anatomical placement of the acetabular component in patients with severe dysplastic osteoarthritis in $28 \%$ of cases resulted in revision operations. This suggests that radical anatomicalbiomechanical reconstruction carried out during operations is not always successful, and high risk of complications not necessarily is warranted. Locomotor apparatus of DOA patients is adapted to the changed position of the hip joint in long period of time (all life). Not always these developed compensatory changes (mostly - in pelvis, lumbar - sacral region, the opposite side knee) are reversible. Therefore, we believe that surgery outcome should be the result of a compromise between the normal pelvic anatomy and how it can be implemented in any given situation of dysplasia. Pre-operative planning plays an important role, and the radiographic placement of hip rotation center is the basis for good clinical outcome. The study data confirmed that during 
radiographic planning anatomic placement of hip rotation center, due to anatomical features of dysplastic joint, not always is possible. When planning the placement of endoprosthesis in joint's primary (anatomical) socket, it's often the case that acetabulum's upper - lateral edge defect stays. Sometimes, more than one-third of acetabular component of endoprosthesis may remain not covered by bone (Figure 4.1a - uncovered part of acetabular component of EP is colored in red) which can contribute to an earlier loosening of endoprosthesis. EP coverage by bone can be increased by grafting of acetabulum with autobone from the femoral head or allobone. But there is another solution - to plan for a smaller size of cementless acetabular component in joint's secondary socket (Fig. 4.1.b). Thus it is possible (without elongation of limb) to achieve both greater acetabular component's coverage by bone and avoid the usage of bone graft (which can sometimes be unsuccessful - bone graft may not heal or can be absorbed).

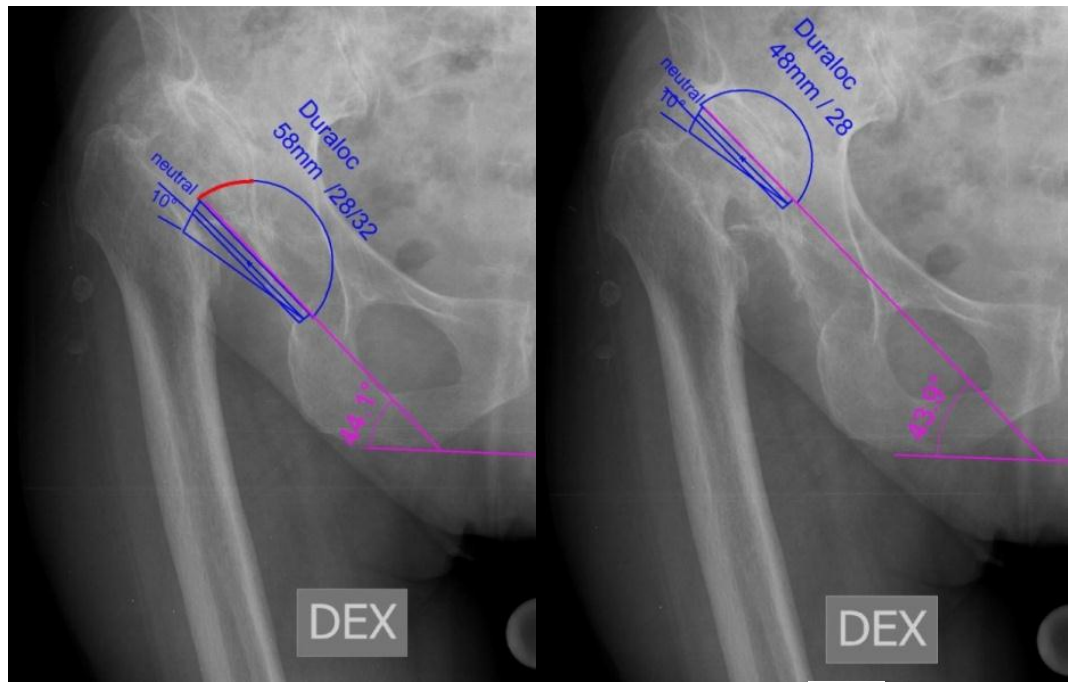

a

$\mathrm{b}$

Figure 4.1. Planning of placement of acetabular component of endoprosthesis a - in joint's primary socket; $b$ - in joint's secondary socket 
Various authors mention different maximum elongation of leg values. Thus, Edward [43] and co-authors believe that elongating the leg during total hip replacement by more than $4 \mathrm{~cm}$ may significantly increase the risk of damaging the sciatic nerve. We believe that planning of the expected (required) leg elongation needs to take into account another important factor - previous operations carried out on the replaceable joint. In cases where surgery has already been performed, scar tissue may contain also the sciatic nerve, and limb elongation by just $3 \mathrm{~cm}$ can lead to traction type nerve damage. We think that when one is planning to elongate a limb by more than $3 \mathrm{~cm}$, when the replaceable hip joint (grade II, III, IV dysplasia, by Crowe) already had been operated, acetabular component of EP has to be placed in the joint's secondary socket. By positioning of the acetabular component of EP in the primary socket in severe DOA patients with structural (irreversible) changes (lumbo sacral region spondiloarthrosis, scoliosis, oblique pelvis), one can gain a significant functional elongation of the limb. It's possible that later compensatory (to equalize leg length) increase of this leg's knee valgus deformation takes place, and develops OA. In cases of pronounced insufficiencies in the medial collateral ligament, treatment of such pathologies may require usage of knee stabilizing EP (which is considerably more expensive than a standard EP) [44].

Important radiographic evaluation characteristic is the distance from the rotation center of hip to the edge of the trochanter major (offset). Its changes during surgery significantly increase or decrease the stretching of abductor muscles which in turn ensures stability of the hip joint. The right offset is a prerequisite for normal muscle functioning and stable (no-waddling) gait. After replacement, acetabular component in DOA patients is mediatized in order to achieve its coverage by bone. As a result, the horizontal location of rotation center of joint decreases, and an adequate offset can be achieved by the EP whose neck's length (hence the offset) can be changed using a modular EP 
head or by selecting specific lateralized EP stems - with a factory-integrated extended EP neck and reduced femoral neck-shaft angle.

Our results indicate that by placing acetabular component of EP in joint's secondary socket during replacement OP in patients with severe dysplasia it's possible to achieve a good functional outcome.

Conversely, placing EP in primary (anatomical) socket in patients with grade III, IV dysplasia increases the potential risk of complications (such as damage to nerves, femoral fractures, elongation of leg). For instance, seven fractures (during surgery) detected in our study happened in the grade III and IV dysplasia patients with acetabular component of EP positioned in the joint's primary (anatomical) socket.

Some authors recommend positioning acetabular component of EP at the level of the anatomical joint socket [45] in combination with a subtrochanteric femoral osteotomy and femoral shortening. It may thus reduce risk of nerve stretching-type injury and avoid elongation of leg. However, the rehabilitation period is very long (up to two years) and place of osteotomy may also do not heal [27]. DOA patients are mostly young (of 20 - 50 years old), so socially active people of working age. Often it is the long period of rehabilitation after operation that discourages application of this method.

The research confirmed our hypothesis that placement of acetabular component of EP in hip's primary (anatomical) socket does not always give the best radiographic and functional outcome. Most of the complications ( 8 out of 10) were observed in patients with pronounced DOA who had acetabular component of EP placed in primary socket (study group K234P). Also both nerve damage cases occurred in patients with acetabular component of EP placed in anatomical localization (control group K1). In one case, when the leg during operation was elongated by $4 \mathrm{~cm}$, the sciatic nerve was found being damaged which manifested itself as paresis of foot. Conversely, in the study 
group K234S (with acetabular component of EP placed in the joint's secondary socket, so after the less radical OP) no complications were observed.

Author has developed the original algorithm where to place the acetabular component of EP (Fig. 4.2.); the choice of placement is related to the grade of dysplasia (by Crowe), the expected elongation of leg and the possibility of achieving adequate coverage of acetabular component by bone in pelvis. 


\section{CONCLUSIONS}

\subsection{Conclusions about pre- and post-operative radiographic analysis of DOA patients}

- $\quad$ Special digital orthopaedic software AGFA Orthopaedic Tools enables a precise pre- and post-operative radiographic analysis and pre-operative planning.

- Replacement results in statistically significant changes in the following hip characteristics (compared with pre-operative data):

- $\quad$ HRC distance is reduced $(\mathrm{p}<0.001)$ in all study groups - this indicates that rotation center of hip is medialized during surgery;

- $\quad$ offset increases $(\mathrm{p}<0.001)$ in all study groups - thus providing joint stability and abductor muscle activity;

- $\quad$ CEA (parameter which characterizes the EP acetabular component's coverage by bone) is increased in all study groups, compared to the preoperative LCEA ( $\mathrm{p}<0.001)$. CEA $<17^{\circ}$ was in $2(4.3 \%)$ replaced hip joints in the control group (K1), in $3(8.8 \%)$ replaced hip joints in the first study group $(\mathrm{K} 234 \mathrm{P})$, and in $4(16.0 \%)$ replaced hip joints in the second study group (K234S). Data indicate that it's extremely difficult to achieve sufficient bone coverage when placing EP in the joint's secondary socket, and this could be understandable in the light of bone mass deficit in severe DOA cases;

- VRC distance decreases in the group K234P (group of severe DOA cases with the acetabular component of EP placed in the joint's primary socket) - this indicates that the rotation center of hip has shifted distally during surgery). 


\subsection{Conclusions about analysis of DOA functional results (pre- and post-operative)}

- According to Merle-d'Aubigne-Postel hip functional status assessment method, the scores before surgery were dramatically poor in all study groups directly on the pain scale (an average of 1.7 points on 6-point scale). Pain - the main indication for joint replacement in both control and study groups.

- Comparing, using Merle-d'Aubigne-Postel hip functional status assessment method, patients who had EP acetabular component placed in anatomical localization with patients who had EP acetabular component placed into the joint's secondary socket, one year after surgery there were no statistically significant differences between groups $(p \geq 0.228)$. The overall result approached the healthy person characteristics, in addition, the group of EP acetabular component placed in the secondary socket (K234S) had even slightly better results than in other two groups ( $\mathrm{K} 1$ and $\mathrm{K} 234 \mathrm{P})$ with acetabular component placed in the primary socket.

- The results of IGA (not earlier than one year after total hip replacement) show that also gait deviation index (GDI) average value discrepancies between groups are not statistically significant $(\mathrm{p}=0.235)$, or the current amount of data is not sufficient to demonstrate the opposite.

- Our study did not reveal any direct leg's functional length correlation with anatomical elongation of leg during surgery. Performing the measurements a year or more after the replacement, it is evident that part of patients also after surgery experience body countervailing mechanisms developed during lifetime which try to correct leg length discrepancy by using the pelvic tilt and hypermobility or curving of lumbo - sacral region of spine. 


\subsection{Conclusions about evaluation of post-operative complications in relation to the placement of acetabular component of endoprosthesis}

- All complications, observed in the study, were in patients who had acetabular component of EP placed in anatomical socket.

- Risk of complications statistically significantly increases in patients with the following characteristics:

- $\quad$ before OP, Wiberg's LCEA $<5.11^{\circ}(\mathrm{p}=0.032)$;

- $\quad$ in pre-operative measurements, offset is reduced $(\mathrm{p}<0.001)$ and HRC distance is increased $(\mathrm{p}<0.001)$;

- $\quad$ it's necessary to elongate the limb $>4 \mathrm{~cm}$ (or $>3 \mathrm{~cm}$ in patients with a history of surgery in replaceable joint);

- $\quad$ before OP, found grade III, IV dysplasia (by Crowe classification).

- No complications, observed in the study, were in patients who had acetabular component of EP placed in secondary socket.

\section{Resume}

1. Placement of acetabular component of EP in primary socket in severe DOA cases (grade II, III, IV dysplasia by Crowe classification) significantly increases the risk of intraoperative complications.

2. In cases of severe hip joint DOA, placement of acetabular component of EP in the secondary socket provides a good functional outcome, as well as reduces the potential risk of complications. 


\section{PRACTICAL RECOMMENDATIONS}

1. Use the digital orthopedic software AGFA Orthopaedic Tools in preoperative planning.

2. During the replacement surgery, use the developed algorithm how to choose the placement of acetabular component of endoprosthesis (Fig. 6.1.), thus reducing the likelihood of intra- and post-operative complications.

3. Implement the recommended algorithm, using cementless fixation of acetabular components of endoprosthesis.

4. EP cementless acetabular component's inclination (abduction) angle in pelvis is allowed between $35^{\circ}$ and $55^{\circ}$. During the operation, it is possible to adjust this angle, using the polyethylene inserts with antiluxation edge $\left(10^{0}, 20^{0}\right)$.

5. If CEA is less than $17^{\circ}$, the EP acetabular component's coverage by bone is insufficient (one has to plan bone grafting for acetabulum using autobone made of the femoral head, or using allobone).

6. In case of DOA patients with grade IV dysplasia (by Crowe), it is desirable to conduct CT examination to determine the volume of pelvic bone.

7. In cases of severe DOA patients, after operation it is recommended to perform the instrumental gait analysis for accurate further rehabilitation planning. 
The algorithm of the placement of acetabular component of endoprosthesis in dysplastic osteoarthritis patients

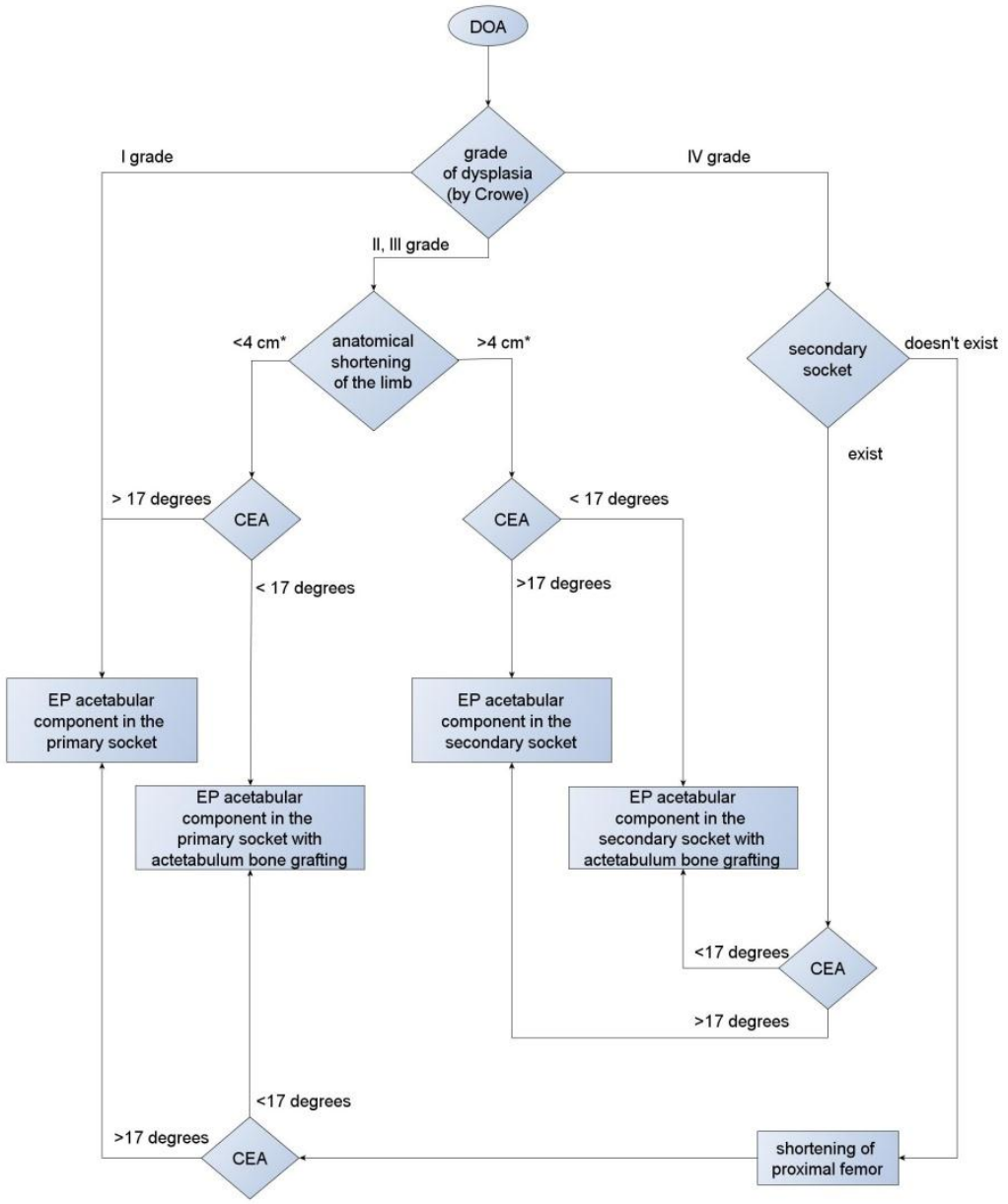

Figure 6.1. The algorithm of placement of acetabular component of endoprosthesis in dysplastic osteoarthritis patients

* - if replaceable joint already had been operated then elongation of the limbs is admissible by no more than $3 \mathrm{~cm}$ 


\section{PUBLICATIONS ABOUT THE STUDY TOPICS}

1. Zēbolds S. Endoprotezēšana pacientiem ar displastisku osteoartrītu. (Arthroplasty in patients with the dysplastic osteoarthritis.) RSU Zinātniskie raksti, Rīga, 2009; 182. - 189.

2. Zēbolds S., Jumtins A. The evaluation of early results after total hip replacement in dysplastic hip patients. Acta Chirurgica Latviensis 2010;(10 / 2 ):53. -57 .

3. Zēbolds S., Jumtiņš A. Gūžas locītavas endoprotēzes rotācijas centra radiolog̣iskā plānošana pacientiem ar displastisku osteoartrītu. (Radiographic planning of rotation center of hip endoprosthesis in patients with dysplastic osteoarthritis.) RSU Zinātniskie raksti, Rīga, 2010; 190. - 197.

4. S.Zebolds, V.Goncars, I.Zommers, K.Kalnberzs. Both Knee Re-revision Operations with Different Types of Endoprosthesis after Septic Complications. Acta Chirurgica Latviensis 2011;(11): 167.-171.

5. Latvian Republic patent No.14412 (Patent publication date 20.01.2012.) Gūžas locītavas endoprotēzes acetabulārā komponenta izkustēšanās prognozēšanas pañēmiens displastiskā osteoartrīta pacientiem. (Method of prognostication of the loosening of the acetabular component of hip endoprosthesis in dysplastic osteoarthritis patients.) Authors: S. Zēbolds, A. Jumtins.

6. Silvestris Zebolds, Valdis Goncars, Ints Zommers, Konstantins Kalnberzs. The Management of Extensive Bone Loss in Primary and Revison Total Knee Replacement. Acta Chirurgica Latviensis 2012;(12):32.-35.

7. Ints Zommers, Bernd Gondolph-Zink, Konstantins Kalnberzs, Andris Jumtins, Silvestris Zebolds, Valdis Goncars. The Prevalence of Heterotopic Ossification after Primary Total Hip Arthroplasty. Publikācija (manuskripta Nr.298) pien̦emta publicēšanai žurnālā "Medicina" (Kaunas, Lietuva), raksts 20 lappuses.

8. Silvestris Zebolds, Andris Jumtins. Intraoperative and Early Complications after THA in Dysplastic Hips. Publikācija iesniegta publicēšanais žurnālā Indian Journal of Orthopaedics, raksts - 12 lappuses. 


\section{REPORTS ABOUT THE RESEARCH TOPIC}

1. Kalnberzs K., Goncars V., Zebolds S., Zommers I. Severe Primary and Revision TKR with Rotating Hinge. Baltijas valstu traumatologu un ortopēdu IV kongress Vilņāa (Lietuva), 23 - 24.04.2010. ( $4^{\text {th }}$ Congress of Baltic traumatologists and orthopaedics in Vilnius (Lithuania))

2. Kalnbērzs K., Gončars V., Zēbolds S., Zommers I. The Mid-term Results in THR Revision with MP Reconstruction Stem. Baltijas valstu traumatologu un ortopēdu IV kongress Viḷnā (Lietuva), 23 - 24.04.2010. (4th Congress of Baltic traumatologists and orthopaedics in Vilnius (Lithuania))

3. Zēbolds S., Jumtiňš A . Gūžas locītavas ektopijas korekcija pēc endoprotezēšanas displastiskā osteoartrīta pacientiem. 5. Ikgadējā Latvijas traumatologu un ortopēdu konference, Rīga, 25.03.2011. ( $5^{\text {th }}$ Annual conference of Latvian traumatologists and orthopaedists)

4. Zēbolds S., Gončars V., Kalnbērzs K. , Zommers I. Mūsu pieredze primārajā un revīzijas cel̦a locītavas endoprotezēšanā ar rotējošās engées protēzi. 5. Ikgadējā Latvijas traumatologu un ortopēdu konference, Rīga, 25.03.2011. ( $5^{\text {th }}$ Annual conference of Latvian traumatologists and orthopaedists)

5. Zēbolds S., Jumtiņš A. Viberga leņķa izmaiņas displastiskā osteoartrīta pacientiem pēc gūžas locītavas endoprotezēšanas (Wiberg's angle changes in dysplastic osteoarthritis patients after hip replacement.) RSU Zinātniskā konference, Rīga, 14. - 15.04.2011. (Scientific Conference of Riga Stradin̄š University, Riga)

6. Zebolds S., Jumtins A. The comparison of preoperative planning and postoperative radiographic outcome after THR in dysplastic hip patients . Stenda referāts (e-posters) XII EFORT kongresā (Kopenhāgena (Dānija), 1.4.06.2011. (12th EFORT Congress poster (e-posters) (Copenhagen (Denmark))

7. Kalnbērzs K., Gončars V., Zēbolds S., Zommers I. The management of extensive bone loss in primary and revision TKR. Stenda referāts (e-posters) XII EFORT kongresā (Kopenhāgena (Dānija), 1.- 4.06.2011. (12th EFORT Congress poster (e-posters) (Copenhagen (Denmark))

8. Kalnbērzs K., Gončars V., Zēbolds S., Zommers I. The mid-term results in revision THR in patients with proximal femoral bone loss. Stenda referāts (eposters) XII EFORT kongresā (Kopenhāgena (Dānija), 1.- 4.06.2011. (12th EFORT Congress poster (e-posters) (Copenhagen (Denmark))

9. S.Zēbolds, A. Jumtiņš, Z.Pavāre, T.Ananjeva. Funkcionālo rezultātu analīze displastiskā osteoartrīta pacientiem pēc gūžas locītavas 
endoprotezēšanas.(Analysis of functional results of dysplastic osteoarthritis patients after hip replacement.) RSU Zin. konference, Rīga, 30.03.2012. (Scientific Conference of Riga Stradiņš University, Riga)

10. S.Zebolds, A.Jumtins, Z.Pavare, T.Ananjeva. Gūžas locītavas rotācijas centra novietojuma ietekme uz displastiskā osteoartrīta pacientu gaitu pēc endoprotezēšanas operācijas. (Effects of placement of rotation center of hip joint on dysplastic osteoarthritis patients' gait after replacement surgery.) 6 . ILTOK konference, Rīga, 19.05.2012. (6 ${ }^{\text {th }}$ ILTOK Conference, Riga)

11. S.Zebolds,MD.,A.Jumtins, $\mathrm{MD}, \mathrm{PhD}, \mathrm{Z}$.Pavare, $\mathrm{MD}, \mathrm{PhD}, \mathrm{T}$.Ananjeva. Gait analysis after total hip arthroplasty in dysplastic hip patients. Stokholma(Zviedrija). Stenda referāts (posteris) 21.ESMAC kongresāa, 12.15.09.2012. (21st ESMAC Congress poster)

12. Silvestris Zebolds, Andris Jumtins, Zane Pavare, Tatjana Ananjeva, Aleksejs Smolovs. Gait Analysis in Dysplastic Hip Patients. Mutisks referāts, 4st International Interdisciplinary Scientific Conference SOCIETY HEALTH WELFARE , Riga, 22. - 23.11.2012.

13. Silvestris Zēbolds, Andris Jumtiņš. Komplikācijas pēc gūžas locītavas endoprotezēšanas displastiskā osteoartrīta pacientiem. (Complications after hip replacement in dysplastic osteoarthritis patients.) Mutisks referāts. (Oral presentation.) RSU Zinātniskā konference, Rīga, 21. - 22.03.2013. (Scientific Conference of Riga Stradiņš Uiversity, Riga)

14. S.Zebolds, A.Jumtins. Radiographic and functional outcome after total hip arthroplasty in dysplastic hips due to the placement of acetabular component. Stenda referāts (posteris) XIV EFORT kongresā, Stambula (Turcija), 05. - 08.06.2013. (14th EFORT congress poster, Istanbul (Turkey))

15. S.Zebolds, A.Jumtins. Complications after THR in dysplatic hip patients. Oral presentation. The $5^{\text {th }}$ Baltic Congress of Traumatalogy and Orthopaedics, Riga, 20. - 21.09.2013. 


\section{REFERENCES}

1. Dorr LD, Tawakkol S, Moorthy M, Long W, Wan Z. Medial protrusio technique for placement of a porous-coated, hemispherical acetabular component without cement in total hip arthroplasty in patients who have acetabular dysplasia. JBJS Am 1999; 81: 83-91.

2. Murphy SB, Ganz R, MØuller ME. The prognosis in untreated dysplasia of the hip. A study of radiographic factors that predict the outcome. JBJS Am 1995; 77: 985 989.

3. Ermiş MN, Dilaveroğlu B, Erçeltik O, Tuhanioğlu U, Karakaş ES, Durakbaşa MO. Intermediate - term results after uncemented total hip arthroplasty for the treatment of developmental dysplasia of the hip. Eklem Hastalik Cerrahisi 2010; 21: 15 - 22.

4. Becker DA, Gustilo RB. Double - chevron subtrochanteric shortening derotational femoral osteotomy combined with total hip arthroplasty for the treatment of complete congenital dislocation of the hip in the adult. Preliminary report and description of a new surgical technique. J Arthroplasty 1995; 10: 313 - 318.

5. Maeyama A, Naito M, Moriyama S, Yoshimura I. Evaluation of dynamic instability of the dysplastic hip with use of triaxial accelerometry. JBJS Am 2008; 90: 85 - 89.

6. National Joint Registry for England and Wales; 7th Annual Report, 2010. Available at: http://www.njrcentre.org.uk/NjrCentre/LinkClick.aspx?fileticket=QkPI7kk6B2E\%3d\&tabid=6\&mid=523. Accessed October 6, 2011.

7. American Academy of Orthopaedic Surgeons. Available at: http://orthoinfo.aaos.org. Accessed October 6, 2011.

8. Henrich C, Engelmaier F, Mehling I, et al. Cementless acetabular reconstruction and structural bone - grafting in dysplastic hips. Surgical technique. JBJS 2007; 89: 54 673.

9. Crowe JF, Many VJ, Ranawat CS. Total hip replacement in congenital dislocation of the hip. JBJS 1979; 61 A : $15-23$.

10. Silber DA, Engh CA. Cementless total hip arthroplasty with femoral head bone grafting for hip dysplasia. J Arthroplasty 1990; 5: 235 - 240.

11. Park MS, Kim KH, Jeong WC. Transverse subtrochanteric shortening osteotomy in primary total hip arthroplasty for patients with severe hip developmental dysplasia. $\mathbf{J}$ Arthroplasty 2007; 22: 1031 - 1036.

12. Tabutin J, Cambas PM. Hip arthroplasty up to the age of 30 and considerations in relation to subsequent revision. Hip Int 2009; 19: 201 - 205.

13. Dunn HK, Hess WE. Total hip replacement for severe osteoarthrosis secondary to dysplasia of the hip replacement. Clin Orthop 1976; 121: $20-32$.

14. Morscher EW. Total hip replacement for osteoarthritis in congenital hip dysplasia. European Instructional Course Lectures 1995; 2: 1 - 8 .

15. Harris WH, Crother O, Oh J. Total hip replacement and femoral head bone-grafting for severe acetabular defficiency in adults. JBJS 1977; 59 A: 752 - 759. 
16. Schutzer SF, Harris W. H. High placement of porous - coated acetabular componenets in complex total hip arthroplasty. J Arthroplasty 1994; 9: 359 - 367.

17. Schöllner C, Decking J, Eckardt A. The Artek cup for total hip replacement of dysplastic hip joints. Arch Orthop Trauma Surg 2003; 123: 299 - 304.

18. Hendrich C, Engelmaier F, Mehling I, et al. Cementless acetabular reconstruction and structural bone - grafting in dysplastic hips. Surgical technique. JBJS 2007; 89: $54-67$.

19. Hartofilakidis G, Karachalios T, Stamos KG. Epidemiology, demographics, and natural history of congenital hip disease in adults. Orthopedics 2000; 8: 823 - 827 .

20. Lund KH, Tennansen NB. Hip replacement for congenital dislocation and dysplasia. Acta Orthop Scand 1985; 56: $464-468$.

21. Symeonides PP, Poumaras J, Petsatodes G, et al. Total hip arthroplasty with cement in neglected congenital dislocation of the hip. Clin Orthop 1997; 341: 55 - 61.

22. Charnley J. Low Friction Arthroplasty of the Hip Theory and Practise. Berlin: Springer - Verlag, 1979; 376.

23. Bicanic G, Delimar D, Delimar M, et al. Influence of the acetabular cup position on hip load during arthroplasty in hip dysplasia. Int Orthop 2009; 33: 397 - 402.

24. Harley JM, Wikinson JA. Hip replacement for adults with unreduced congenital dislocation a new surgical technique. JBJS Br 1987; 69: 752 - 755.

25. Harris WH. Reconstruction at a high hip center in acetabular revision surgery using a cementless acetabular component. Orthopedics 1998; 21: 991 - 992.

26. Bozic KJ, Freiberg AA, Harris WH. The high hip center. Clin Orthop Relat Res 2004; 420: 101 - 105.

27. Klapach AS, Callaghan JJ, Miller KA, et al. Total hip arthroplasty with cement and without acetabular bone graft for severe hip dysplasia. JBJS Am 2005; 87: 280 285.

28. Merle d' Aubigne R, Postel M. Functional results of hip arthroplasty with acrylic prosthesis. JBJS 1954; 36: 45.

29. Perry J, Schwartz MH, Rozumalski A. The gait deviation index: A new comprehensive index of gait pathology. Gait \& Posture 2008; 28: 351- 357.

30. Zebolds S, Jumtins A. Early Results after Total Hip Replacement in Dysplastic Hip Patients. Acta Chir. Latviensis 2010; 10 (2): 53 - 57.

31. Crowe JF, Many VJ, Ranawat CS. Total hip replacement in congenital dislocation of the hip. JBJS 1979; 61A: 15 - 23.

32. Wilkinson JA. A post - natal survey for congenital displacement of the hip. JBJS Br Feb 1972; 54(1): 40 - 9 [Medline].

33. Zebolds S, Jumtins A. Early Results after Total Hip Replacement in Dysplastic Hip Patients. Acta Chir. Latviensis 2010; 10 (2): 53 - 57.

34. Erdemli B, Yilmaz C, Atalar H, Guzel B, Cetin I. Total hip arthroplasty in developmental high dislocation of the hip. J Arthroplasty 2005; 20: 1021 - 1028.

35. Konyves A, Bannister GC. The importance of leg lenght disrepancy after total hip arthroplasty. JBJS Br 2005; 87: 155 - 157.

36. White TO, Dougall TW. Arthroplasty of the hip. Leg lenght is not important. JBJS Br 2002; 84: 335 - 338 . 
37. Krych AJ, Howard JL, Trousdale RT et al. Total Hip Arthroplasty with Shortening Subtrochanteric Osteotomy in Crowe Type-IV Developmental Dysplasia. JBJS Am 2009; 91: 2213 - 2221.

38. Sanchez - Sotelo J, Berry DJ, Trousdale RT, Cabanela ME. Surgical Treatment of Developmental Dysplasia of the Hip in Adults: II Arthroplasty Options. J Am Acad Orthop Surg 2002; 10: 334 - 344.

39. Carlsson A, Bjorkman A, Ringsberg K, T von Schewelov. Untreated congenital and posttraumatic high dislocation of the hip treated by replacement in adult age: 22 hips in 16 patients followed for 1-8 years. Acta Orthop Scand 2003; 74: 389 - 396.

40. Shen B, Yang J, Wang L, Zhou ZK, Kang PD, Pei FX. Midterm results of hybrid total hip arthroplasty for treatment of osteoarthritis secondary to developmental dysplasia of the hip-Chinese experience. J Arthroplasty 2009; 24: 1157 - 1163.

41. Kim YH, Kim JS. Total hip arthroplasty in adult patients who had developmental dysplasia of the hip. J Arthroplasty 2005; 20: 1029 - 1036.

42. Harris WH. The problem is osteolysis. Clin Orthop Relat Res 1995; 311: 46 - 53.

43. Edwards BN, Tullos HS, Nobel PC. Contributory factors and etiology of sciatic nerve palsy in total hip arthroplasia. Clin Orthop 1987; 218: 136 - 141.

44. Zebolds S, Goncars V, Zommers I, Kalnberzs K. The Management of Extensive Bone Loss in Primary and Revision Total Knee Replacement. Acta Chirurgica Latviensis 2012 (12): $32-36$.

45. Ziegler J, Thielemann F, Mayer - Athenstaedt C, Günther KP. The natural history of developmental dysplasia of the hip: A metaanalysis of the published literature [German]. Orthopade May 17 2008; epub ahead of print [Medline]. 